\title{
Review on Additive Manufacturing of Catalysts and Sorbents and the Potential for Process Intensification
}

\author{
Leon R.S. Rosseau ${ }^{1}$, Vesna Middelkoop ${ }^{2}$, Hans A.M. Willemsen ${ }^{3}$, Ivo Roghair ${ }^{1}$ and \\ Martin van Sint Annaland ${ }^{1 *}$
}

${ }^{1}$ Department of Chemical Engineering and Chemistry, Eindhoven University of Technology, Eindhoven, Netherlands, ${ }^{2}$ Sustainable Materials Management, Flemish Institute for Technological Research, Mol, Belgium, ${ }^{3} 3 D$-cat B.V., Bergen, Netherlands

\section{OPEN ACCESS}

Edited by:

Harshul Thakkar,

Los Alamos National Laboratory

(DOE), United States

Reviewed by:

Khaled Baamran,

Missouri University of Science and

Technology, United States

Pshtiwan Shakor,

University of Technology Sydney,

Australia

Jamie Thompson,

(in Stealth Mode), United States

*Correspondence:

Martin van Sint Annaland

M.v.SintAnnaland@tue.n

Specialty section:

This article was submitted to

Materials Process Engineering,

a section of the journal

Frontiers in Chemical Engineering

Received: 13 December 2021

Accepted: 31 January 2022

Published: 18 February 2022

Citation:

Rosseau LRS, Middelkoop V,

Willemsen HAM, Roghair I and

van Sint Annaland M (2022) Review on Additive Manufacturing of Catalysts and Sorbents and the Potential for

Process Intensification.

Front. Chem. Eng. 4:834547.

doi: 10.3389/fceng.2022.834547
Additive manufacturing of catalyst and sorbent materials promises to unlock large design freedom in the structuring of these materials, and could be used to locally tune porosity, shape and resulting parameters throughout the reactor along both the axial and transverse coordinates. This contrasts catalyst structuring by conventional methods, which yields either very dense randomly packed beds or very open cellular structures. Different 3Dprinting processes for catalytic and sorbent materials exist, and the selection of an appropriate process, taking into account compatible materials, porosity and resolution, may indeed enable unbounded options for geometries. In this review, recent efforts in the field of 3D-printing of catalyst and sorbent materials are discussed. It will be argued that these efforts, whilst promising, do not yet exploit the full potential of the technology, since most studies considered small structures that are very similar to structures that can be produced through conventional methods. In addition, these studies are mostly motivated by chemical and material considerations within the printing process, without explicitly striving for process intensification. To enable value-added application of 3D-printing in the chemical process industries, three crucial requirements for increased process intensification potential will be set out: i) the production of mechanically stable structures without binders; ii) the introduction of local variations throughout the structure; and iii) the use of multiple materials within one printed structure.

Keywords: additive manufacturing, 3D-printing, process intensification, catalyst shaping, packed bed reactors, catalysis, sorbents

\section{INTRODUCTION}

Catalysis is a field in chemical engineering which has made tremendous progress in the past decades. A variety of technological innovations, such as the scale-up of high throughput experimentation and increasing computational power for theoretical calculations, has led to a vast increase in both fundamental understanding and commercialization of novel catalytic processes (Derouane et al., 2000; Van der Borght et al., 2015; Friend and Xu, 2017). From the chemist's perspective, the development of a catalyst is commonly concluded with a validation of the catalyst in its intended reactive conditions, on a (sub-) Gram scale. However, after the optimally performing catalytic material is selected, engineering considerations relating to the catalyst's incorporation into a reactor remain. More specifically, the shaping of the catalytic material or, along the same line of reasoning, sorbent materials, takes the challenges from the molecular scale to the scale of the reactor, imposing 
new demands related to reactor engineering and process intensification (Bellefon, 2002; Mitchell et al., 2012, 2013). These engineering requirements revolve around designing the reactor and overall process such, that the productivity is high, energy demand low, and footprint small. This is done in an effort to reduce the capital expenditures, the utility consumption and the $\mathrm{CO}_{2}$ emissions and to accommodate for the limited space at chemical plant facilities. Critical design variables in addressing these challenges are the heat and mass transfer properties and the mixing behavior of the reactor, along with the regular operating parameters. All of these variables are heavily influenced by the configuration of the reactor and the shape of the catalyst (Akhtar et al., 2014; Gascon et al., 2015).

In packed bed reactors, the catalyst geometry is directly related to the catalyst weight per volume of reactor, the fluid-solid interfacial area and the macro-porosity or gas holdup (in this work we will consider heterogeneous gas phase reactions, but similar arguments equally apply to heterogeneous liquid phase reactions). This impacts the observed reaction rates, as the reaction rate generally depends on the catalyst weight and/or interfacial area (Pangarkar et al., 2008; Vervloet et al., 2013). In addition, the macro-porosity governs the ratio of reactant to catalyst, which impacts the residence time and in turn, the Weight Hourly Space Velocity (WHSV). In general, this parameter is optimized to ensure that the products do not spend more time in the reactor than required, since high productivity is crucial. Specifically for systems of multiple reactions, tuning these operating variables is critical, since the selectivity towards a desired product is heavily dependent on the residence time (Silla, 2003). Another relevant effect of the catalyst geometry is the degree of dispersion and backmixing it causes, which determines the Residence Time Distribution (RTD). Often, the degree of backmixing is expressed in relation to two limiting situations; complete backmixing and no backmixing, represented by the Continuously Stirred Tank Reactor (CSTR) and the Plug Flow Reactor (PFR), respectively (Barnard, 1985). The latter is usually preferred for its improved conversion of any reaction with a positive order, as well as improved selectivity towards the targeted product (depending on the reaction orders of the main and consecutive or parallel reactions). However, reactors rarely attain true PFR behavior in practice. Therefore, a consideration of the residence time distribution and its effect on the conversion and selectivity is required (Levenspiel and Bischoff, 1959; Nauman, 1981; Waldram, 1985).

These parameters determine the direct effects of catalyst structuring on the kinetic performance of a reaction. For a complete analysis, however, operating characteristics that are vital to the engineering design need to be considered. Firstly, the influence that a reactor internal has on macroscopic fluid flow is not just limited to the residence time distribution. As the catalyst geometry guides the flow of the fluid, the transfer of mass and heat through the reactor are influenced. The first of these phenomena, mass transfer, is critical since it has the potential to lower the observed reaction rate. In certain situations, the transport of mass to the active sites is slower than the kinetic rate and hence the observed rate is lower (Rezaei and Webley, 2010). In addition, the heat transfer is important since a mismatch in thermal reaction effects and effective heat transfer coefficient may introduce unwanted temperature gradients inside the catalyst and the reactor. In turn, these temperature gradients may be detrimental to conversion and selectivity (Lerou and Froment, 1977). In addition, hot spot formation may lead to thermal runaway, material degradation or perhaps even reactor clogging due to coking (Kapteijn and Moulijn, 2020).

A final parameter vital to the reactor performance and overall process efficiency is the pressure drop, which represents the amount of resistance that the reactor internals offer against the fluid flow. This parameter plays a key role in optimizing the mechanical engineering aspects of the process design; a high pressure drop requires higher energy input for the feed compressors and pumps and this may decrease the overall process efficiency and increase the $\mathrm{CO}_{2}$ footprint (Afandizadeh and Foumeny, 2001). Process equipment should also be constructed to handle the higher pressure, which increases the capital expenditures. More delicate is the influence of pressure drop on reaction rates; many gas phase reactions have kinetic rate equations with pressure dependency, and a pressure gradient along the reactor may influence the conversion and selectivity.

In addition, considerations regarding safety may come into play in the selection of a catalyst geometry. For example, a lower apparent catalyst density may require oversizing of the reactor for the same throughput. This is directly related to process safety, as a larger reactor with a larger amount of reactant brings along increased risks (Etchells, 2005; Hendershot, 2018).

Having introduced the relevant variables that play a role in catalyst (and sorbent) shaping considerations, the various shaping options available can be discussed. In this review, granules, pellets, extrudates, honeycomb monoliths and foams will be considered as established techniques. An attractive alternative to these conventional shaping technologies, additive manufacturing (AM), or 3D-printing, of catalysts and sorbents (where they are considered as ceramic materials) has only taken off in the last couple of years. One of the major advantages of AM is its disruptive approach to the economy of scale and the ability to produce custom components to order, which, for example, makes it ideal for manufacturing in space (Prater et al., 2018). For the structuring of catalysts and sorbents specifically, this technology holds potential for providing a very high degree of design freedom, which allows for the tailoring of structures to specific operating windows and overcome the limitations of conventional shaping methods. Most interesting in this regard is the spatial variations of catalyst geometry that can be created throughout the reactor. One of the reasons this is an interesting approach is that it can, amongst others, mitigate hot spots that are often found in conventional packed bed reactors. The literature already contains quite a number of excellent reviews on the potential of additive manufacturing for chemical engineering, but many of these publications tend to focus on the chemical aspect of the printing process (Bara et al., 2015; Zhou and Liu, 2017; Parra-Cabrera et al., 2018; Gupta et al., 2019b; Kotz et al., 2019; Gordeev and Ananikov, 2020; Zentel et al., 2020; Agrawaal and Thompson, 2021; Lawson et al., 2021b). This includes detailed studies and their considerable scope on the 
formulation of the printing ink, optimization of the printing process and assessment of the chemical and mechanical properties of the printed structures. Whilst these are important technological aspects to consider, the main objective of a novel shaping technology should be kept in mind: process intensification. Hence, the current work will only provide a brief introduction to mature technologies, along with a general idea of the sort of structures that can be created with them. Subsequently, an analysis will be provided of the literature on benchmarking 3D-printed catalyst structures against their conventional counterparts, packed bed reactors, in an effort to achieve process intensification. Since 3D-printing technologies for ceramic materials are not yet deployed on a truly commercial scale, there is little concrete knowledge on the windows of operation. However, with the reviewed cases and process intensification principles in mind, the potential operating benefits of 3D-printed structures over conventional technologies can be considered. Such an analysis is vital, since it should be realized that the use of additive manufacturing to produce components in bulk is not an obvious choice. Currently, $3 \mathrm{D}$-printing of catalysts and sorbents is more expensive and labor-intensive than conventional processes for the shaping of these materials. Hence, the operational benefits of using 3Dprinted structures should outweigh the additional cost to provide a viable addition to the shaping technologies currently available. These benefits are likely found in a "sweet spot" of medium catalyst holdup, low pressure drop and tunable transport properties as this combination is difficult to achieve through the use of conventional methods. The "sweet spot" concept will be used in the coming sections to discern between the possibilities of additive manufacturing and conventional methods in terms of process intensification potential.

In the remainder of this work, the potential for shaping sorbents will be discussed alongside shaping catalysts, and the word catalyst will be used to represent sorbent materials as well. This is done since they are generally in a similar class of materials and feature similar printing protocols. Sorbent materials can be used in various processes as a means of process intensification, through the integration of reaction and separation (Barelli et al., 2008; Zhu et al., 2020). It will be argued that 3D-printing of sorbent and catalyst, either as separate structures or in an integrated multi-material configuration, holds potential for key applications in the chemical process industries.

\section{CONVENTIONAL SHAPING METHODS}

To provide a benchmark of the available technologies against which a 3D-printed catalyst can be compared for application in a packed bed reactor, five classes of conventionally shaped catalyst are reviewed in this section. The basic working principles of the shaping technologies are given, discussing the properties of the shaped body, along with possible constraints on materials, size, porosity and mechanical stability. This will be followed by considerations on the incorporation of the shaped catalyst in a reactor. Finally, qualitative operating windows for the process intensification design parameters are defined to provide a basis for comparison between the different shaping technologies. With regard to the latter, there is no quantitative information readily available for the more complex shapes produced by pelleting or extrusion, since exact geometries are often proprietary information, as they are mostly developed and manufactured within industrial $\mathrm{R} \& \mathrm{D}$ rather than academic catalysis research (Akhtar et al., 2014; Lakiss et al., 2020).

An initial consideration for every shaping technology is that the shaped body, also called the green structure, needs to be postprocessed. The post-processing sequence usually starts in a low temperature process with a high heating rate for debinding. This is followed by a high temperature process with a relatively low heating rate for sintering or calcining the material. These operations are accompanied by a significant degree of shrinkage (in the order of $20-30 \%$ ) and porosity changes, and should be conducted carefully to tune the product properties (Kuang et al., 1997; Shang et al., 2015; Li H. et al., 2020; Somton et al., 2020). For shaping by whichever technology, the catalyst or sorbent powder is generally not cohesive enough, and does not possess the mechanical strength required to maintain the shape intended. Hence, binders are added to maintain the shape and achieve the desired mechanical strength. Organic compounds, such as plasticizers, lubricants and peptizers, may be added to ensure that the green structure holds its shape and that the formulation has the desired viscoelastic properties for its shaping method (Mitchell et al., 2013). These organic compounds, however, are inevitably combusted as the structure is post-processed, although organic compounds do not necessarily have to be removed in case of some low temperature sorbent applications (Kraushaar-Czarnetzki and Müller, 2009; Whiting et al., 2019; Grande et al., 2020). Hence, inorganic binders are included to provide rigidity and mechanical strength after post-processing (Akhtar et al., 2014). These inorganic binders are known to slightly reduce the porosity of a catalyst as pores are blocked. In addition, unwanted chemical effects may be introduced. In the first place, the observed reaction rate may be lower, as the catalyst is diluted with binder material (Li Z. et al., 2020). A second effect may be introduced by the chemical nature of these binders. Especially at high temperatures, common binder materials such as silica, alumina or clay may exhibit catalytic effects which can influence the intended chemical nature of the catalyst (Fougerit et al., 1994; Choudhary et al., 1999; Jasra et al., 2003; Hargreaves and Munnoch, 2013; Bingre et al., 2018; Shen et al., 2019; Vajglová et al., 2019). Considering potentially adverse binder effects and determining the right balance, amount and type of inorganic and organic additives is an essential part of all shaping methods, both for conventional and 3D-printing techniques.

\subsection{Granules}

Spherical particles, or so-called granules or beads, represent the most basic geometry used in fixed bed reactors. Typically, synthesis of catalytic material does not yield crystals of the desired shape and size or adequate mechanical strength and hence, achieving spherical particles requires a separate granulation process. The principle of granulation is relatively simple; wet particles increase in size by rolling amongst catalytic 
material, much like a rolling snowball (Kraushaar-Czarnetzki and Müller, 2009). Granulation processes differ in their working mechanism, as either a rotating pan, an immersed mixer or a fluidized bed can be used. Illustrations of the working mechanisms of these processes can be found in the literature, for example the review by Shanmugam (2015). Whilst these variations may have implications on the production process (e.g., determining whether the particles can be produced continuously or in batches), the product properties that are relevant within the scope of this review are quite similar (Litster and Ennis, 2004). Following granulation, postprocessing is required to completely dry the particles and sinter or calcine them. The obtained particles will likely feature a particle size distribution, as granulation processes are not ideal and induce a residence time distribution on rolling particles. In addition, different granulation processes may have an influence on the sphericity of the particle, but this is a rather delicate issue with many parameters involved (Butensky and Hyman, 1971; Téllez-Medina et al., 2010). The granulation process is suitable for a wide range of catalytic materials, but the porosity may be altered slightly due to particle consolidation (in addition to the general changes that are introduced as a consequence of post-processing) (Iveson et al., 2001; Litster and Ennis, 2004; Pérez-Ramírez et al., 2011).

In some instances, incorporation of the particles into a reactor can be as simple as pouring them in. However, there is often a more detailed protocol available for achieving adequate packing, which is important to avoid particle breakage and attrition (Afandizadeh and Foumeny, 2001). In addition, the packing influences the porosity (profiles) within the bed and an inconsistent packing, especially at low reactor-to-particle diameter ratios, may lead to channelling (Salvat et al., 2005; Duan et al., 2014). This phenomenon is caused by certain pathways presenting less resistance to the fluid travelling through the reactor and therefore becoming preferential. This is problematic since it leads to broadening of the residence time distribution and uneven usage of the bed, which may shift the selectivity or negatively influence the process in general. This phenomenon may increase in severity when multi-tubular reactors are used, as slight differences in packing may lead to maldistribution of the flow between the different tubes (Afandizadeh and Foumeny, 2001). The use of a multi-tubular configuration is, however, often required as radial heat transfer in a packed bed is low and causes hot spots to arise in larger diameter vessels (Shinnar et al., 1992; Vervloet et al., 2013).

If the reactor is packed properly, the performance in terms of process intensification metrics is largely determined by the gas holdup and size and shape of the particles. Whilst particle parameters may be varied, the gas holdup generally attains a value between 35 and $40 \%$ regardless of particle size. These values hold for perfect spheres without particle size distribution, and may differ significantly for poly-disperse systems (Allen et al., 2013; Pottbäcker and Hinrichsen, 2017). As stated, all other parameters relevant to the reactor scale depend on particle size and abundant correlations are available to describe the relevant phenomena. Granulation processes do not impose a practical limit on particle size, which can range from microns to centimeters. Generally, particles in industrial processes are in the millimeter scale (Litster and Ennis, 2004; Hagen, 2015). The choice of particle size is often motivated by two contradictory requirements: the minimization of the internal mass transfer limitations and the minimization of the pressure drop. The first objective, minimizing the internal mass transfer limitations, requires small particles, as diffusion of reactants through large particles is very slow, leading to a lower observed reaction rate and uneven utilization of the particle (Thiele, 1939). On the other hand, a decrease in particle size always leads to an increase in pressure drop, which can decrease the overall process efficiency. A similar design conflict is shown in Figure 1, where the pressure drop and Nusselt number (the dimensionless heat transfer rate) are plotted as a function of the Reynolds number for a packed bed of spheres. In the ideal case, a reactor should be operated with high heat transfer rates and low pressure drop. This, however, can not be achieved simultaneously in a packed bed of spheres, as shown in Figure $\mathbf{1}$.

\subsection{Pellets}

Pellets are cylinder-like geometries, often hollow or with multiple channels, as shown in Figure 2. Forming them is straightforward; catalyst powder is pressed into a millimeter-sized mould with a pressurized die, forcing it to take the shape of the mould (Hagen, 2015). An image of such equipment can be found in the book chapter by Kraushaar-Czarnetzki and Müller (2009). This method can be used to compact the powder so densely that there is no additional need for binder materials, but this depends largely on the physical properties of the powder feed (Ewsuk, 2001). The mechanical strength and structural integrity of the product is very much dependent on the pressure applied, which needs to be rather high. In practice, it is observed that exerting this pressure may break down larger crystals and disrupt existing pore systems (Yakubovich et al., 1984; Li et al., 1991; Ovsienko, 2009; Bingre et al., 2018). Unlike possible particle size distributions introduced through the granulation process, a dry compacting process yields the intended geometry at all times.

Pellets are incorporated in the reactor similarly to particles: by random packing. However, since pellets are often nonsymmetrical structures, packing requires more careful attention and the quality of packing affects the reactor performance to a high degree (Cheng et al., 2010; Moghaddam et al., 2019; George et al., 2021).

The main advantage that pellets offer over spherical granules is the more lenient trade-off between pressure drop and internal mass transfer limitations. The pressure drop often still follows an Ergun-like dependency, albeit with compensation for the nonsphericity and altered packing characteristics (Zou and Yu, 1996; Ozahi et al., 2008). However, the design of cylindrical pellets allows for decoupled tuning of the relevant parameters in both phenomena. By the introduction of internal features into the pellet, the mean path length within the shaped material may be decreased without varying the overall diameter of the pellet. In addition, the freedom of determining the exact shape allows for the tuning of the porosity and fluid-solid interfacial area, important parameters in determining the pressure drop and reactor performance in general. 


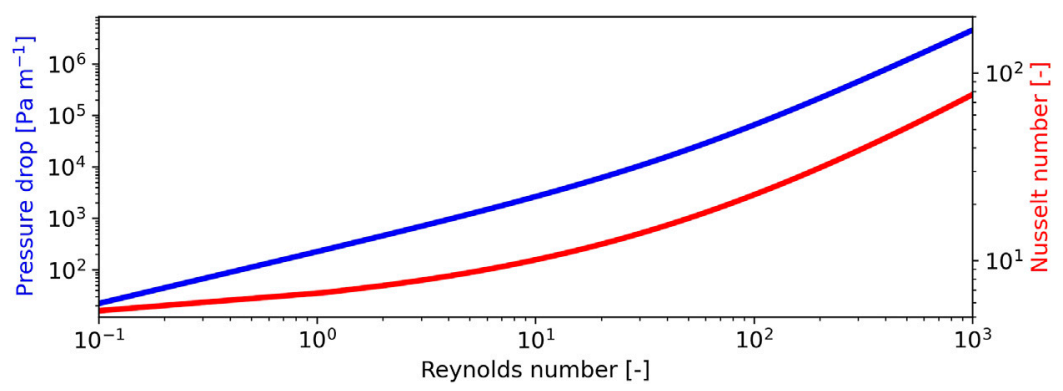

FIGURE 1 | Dependence of pressure drop and heat transfer on the Reynolds number for a packed bed of spheres. Values calculated using the Ergun equation for pressure drop and the Gunn correlation for heat transfer, using the physical properties of nitrogen, a bed porosity of 40\% and a particle size of 1 mm (Ergun, 1952; Gunn, 1978).

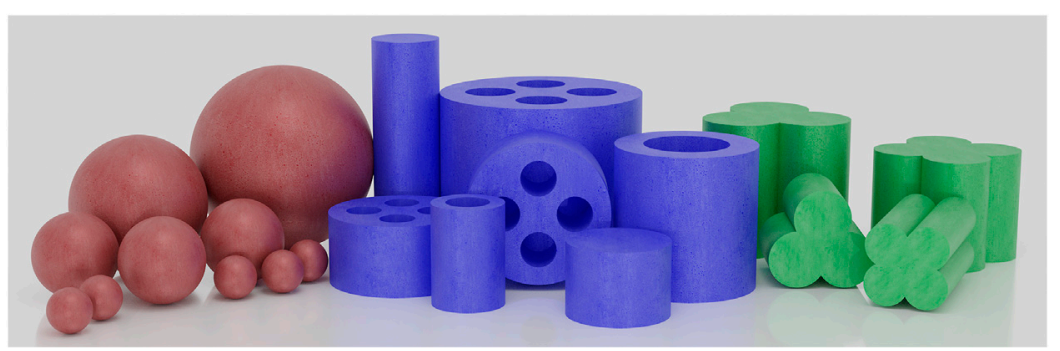

FIGURE 2 | Impression of different conventional catalyst bodies for dense randomly packed beds; spherical particles in red, cylinder-like pellets in blue and multilobe structures in green.

\subsection{Extrudates}

Extrudates represent a class of shaped catalyst materials that is widely applied in industry, such as in large-scale refinery operations. For extrusion, a slurry of catalyst, additives and water is passed through screw extruder and a die to produce a certain shape. A schematic of the working principle of extrusion can be found in the review by Akhtar et al. (2014). Whilst the basic principle is simple, complexity arises when considering the exact composition of the slurry, as it requires the balanced use of, firstly, agents to improve the rheological behavior, secondly, agents to de-agglomerate the particles and, finally, binder materials (Akhtar et al., 2014; Hagen, 2015). This may also restrict the potential applications of extrusion, as the slurry and its constituents may have specific requirements on properties such as $\mathrm{pH}$, which impacts the possibility of using certain materials (Whiting et al., 2019). An advantage of this technology compared to pelleting is that the composition of the slurry, and specifically the liquid-solid ratio, can be tuned to provide additional porosity for the shaped body (Yakubovich et al., 1984; Kraushaar-Czarnetzki and Müller, 2009). The use of dies, generally with millimeter sized features, allows for additional geometrical freedom compared to granules and pellets. Development of the actual shape of the catalyst has largely been an industrial endeavour and therefore, the geometries used are often proprietary information (Ebner and Keppel, 1991; Bazer-Bachi et al., 2014; Lai et al., 2018). Some of the base geometries that are in use are cylinder-like structures that can also be produced by pelleting and multi-lobe structures (also shown in Figure 2), possibly also with helical variations.

Much like pellets and granules, extrudates are often in the millimeter to centimeter scale, and are randomly packed in reactors. The challenge of achieving consistent packing with these often asymmetrical bodies is exacerbated due to the larger degree of geometric freedom, and, again, the quality of the packing may impact the process significantly (Bazmi et al., 2013). Packing procedures and their impact have been the subject of computational studies, which have aided in providing correlations for the flow behavior of randomly packed extrudates (Marek, 2013). The added benefit of using extrudates rather than granules is, as mentioned above, to have flexibility in the surface-to-volume ratio and gas holdup and to tune the pressure drop. As there is no single extrudate shape, it is difficult to show the advantage of this shaping technology in a quantitative way. However, cases from the literature, for example studying trilobe geometry, demonstrate the decreased pressure drop relative to packed beds of spheres (Bambrick, 1986; Novak and Mateer, 1986; Bazmi et al., 2013; Ravindran and Madhu, 2020).

\subsection{Honeycomb Monoliths}

In this work, a distinction is made between honeycomb monoliths and extrudates. While honeycomb monoliths are generally produced by extrusion, their intended application is within standalone reactors rather than as randomly packed beds. 


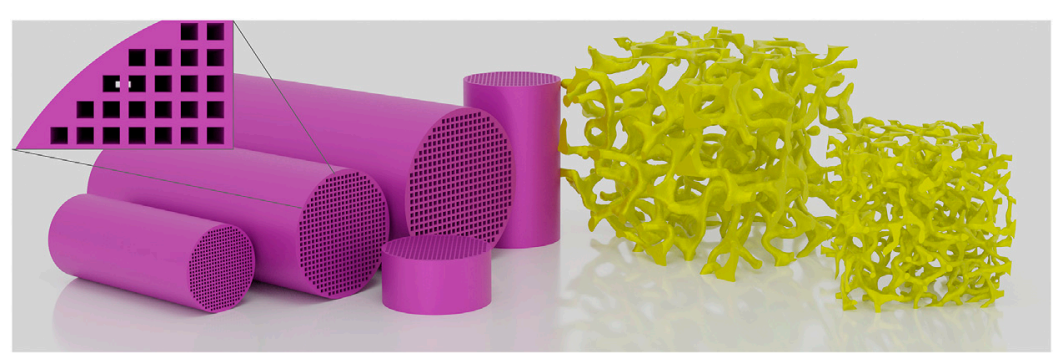

FIGURE 3 | Impression of two conventional cellular structures; honeycomb monoliths in purple and foams in yellow. The foam model is based on a. stl file of Michael Chadband on gradcad.com.

Apart from extrusion of catalytic material, monoliths can also be produced from an inert material (either ceramic or metal) and subsequently be washcoated with catalyst (Hagen, 2015; Govender and Friedrich, 2017; Nijhuis et al., 2001). This latter option is often preferred, since the use of solely catalytic material may yield relatively brittle monoliths with a low thermal conductivity, which are relatively expensive as the bulk of the structure is not catalytically utilized. The main design parameters include the shape of the channels, the cell density, the thickness of the walls and possibly, the thickness of the washcoat. Generally, the individual channels are square in geometry (as shown in Figure 3), but circular or more complex geometries are also described. Typical values for the other parameters include a cell density of tens to hundreds of cells per square inch, a wall thickness of hundreds of microns and a washcoat thickness in the order of tens of microns (Boger et al., 2004; Colombo, 2006; Stutz and Poulikakos, 2008). Whatever the size, significant difficulties can be expected when trying to achieve a uniform coating in all channels due to the interplay of various forces (Nijhuis et al., 2001).

A washcoat configuration does ensure a short diffusive path towards the active sites, but this also implies that the amount of active material per volume of reactor is low. Hence, this configuration is mostly suited for processes that feature severe external or internal mass transfer limitations (Heck et al., 2001). From a reactor engineering point of view, monolith structures present a strong PFR-like character, but this comes at the cost of zero transverse dispersion (unless the walls are permeable) (Kreutzer et al., 2005; Yawalkar et al., 2005). The latter implies that severe temperature gradients over the transverse coordinate may be observed (Tomašić and Jović, 2006). This can be aided by the use of a coated metal monolith, which has high thermal conductivity that can realize effective radial heat transfer, as demonstrated in studies by Groppi et al. (2012); Groppi and Tronconi (2000). The main advantage of a honeycomb monolith is its low pressure drop. Its combined characteristics have motivated the application of this shaped catalyst in fields with high throughput and stringent pressure drop requirements, such as automotive exhaust catalysis or gas separation with sorbents (Boger et al., 2004; Roy et al., 2004; Rezaei and Webley, 2010). The fact that both internal mass transfer limitations and pressure drop can be separately tuned, and near-isothermal operation can be achieved for a washcoated metallic honeycomb monolith, is promising, but for kinetically-limited reaction systems, the reactor may need to be oversized simply due to the low weight of catalyst per unit volume (Arab et al., 2014; Kapteijn and Moulijn, 2020).

\subsection{Foams}

Foams, like honeycombs monoliths, are cellular materials. Likewise, the intended application is as a fixed internal rather than a random packing, which aids in providing consistent packing for multi-tubular configurations (Twigg and Richardson, 2002). The main difference between the two is that foams are 3D-cellular materials rather than the $2 \mathrm{D}$ channels in monoliths. Geometrically, this means that the structure features an interconnected pore network, as shown in Figure 3. This network is established by the foaming process, in which voids are created throughout the catalytic material. This process can be rather complex, and various approaches exist to achieve the foam structure. Often, a sacrificial template (such as organic particles or a polymer sponge) is introduced into a slurry of catalytic material, which is then burned off to create macroscopic voids (Thijs et al., 2004; Studart et al., 2006). Another way of achieving this is by encapsulating gas bubbles (or gas generating materials) into the paste (Colombo, 2006). These technologies have parallels with the generation of meso- or macropores to avoid diffusion limitations in zeolitic materials, albeit several length scales larger (Schwieger et al., 2016). The exact geometry of a foam is often described through idealized repeating units, but it should be kept in mind that the processes described may introduce small spatial inhomogeneities (Lucci et al., 2017; Gancarczyk et al., 2019). Much like the honeycomb monolith, a foam is also often formed from inert material, to be washcoated with catalytic material. Again, this is desired since foams produced entirely from catalytic material may be quite fragile and relatively expensive.

The resulting structures feature very high porosities (typically 75-90\%) and small pores of millimeter size (Thijs et al., 2004; Twigg and Richardson, 2007). The openness of the structure enables transport in the radial direction and as a result of this, hot spots can effectively be suppressed (Li et al., 2015). The heat transfer performance can be further enhanced by exploiting the excellent conductivity of a coated metallic foam (Gascon et al., 2015). The transport of heat and mass in foams have been an active area of research in academia, as demonstrated by numerous 


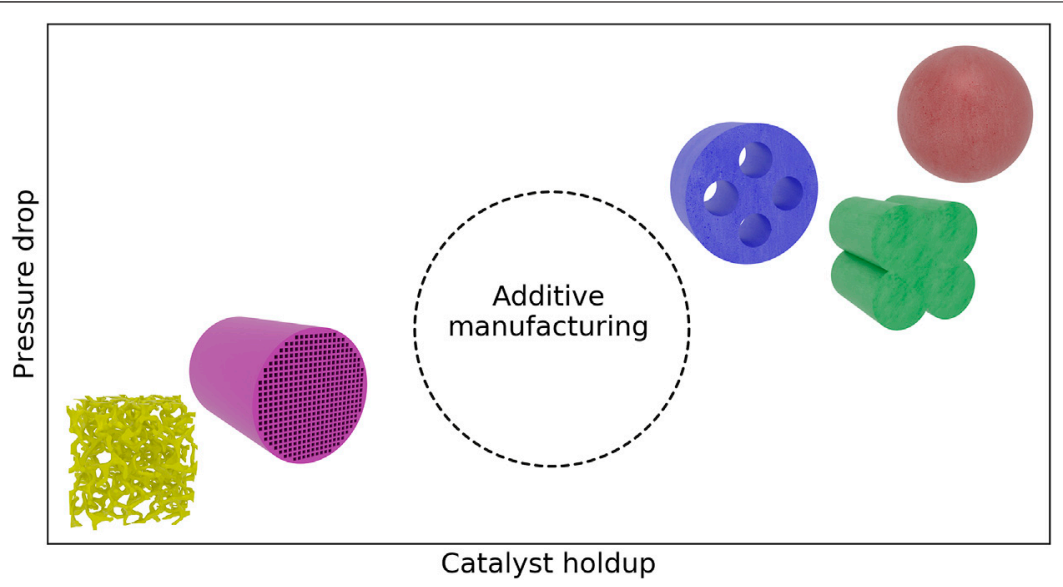

FIGURE 4 | Qualitative comparison of the two classes of conventional catalyst packings in terms of pressure drop and catalyst holdup, alongside the potential 3Dprinting "sweet spot". Structures are not shown to scale.

publications (Dukhan et al., 2014; Bianchi et al., 2012; Giani et al., 2005a,b; Groppi et al., 2007). Going into the exact correlations is beyond the scope of this review, but it is generally found that heat transfer in a foam is of similar order as in packed beds, at very low pressure drop and moderate mass transfer rates (Patcas et al., 2007; Dietrich, 2012). Intensified heat and mass transfer enables foams to provide true process intensification opportunities, but as was mentioned above, the amount of catalytic material is relatively low which could negatively affect the productivity per volume of reactor (Rezaei and Webley, 2010; Gancarczyk et al., 2019). The advantages have been successfully demonstrated in similar applications as selected for the honeycomb monoliths. However, large scale deployment does not seem imminent (Pestryakov et al., 1996; Patcas et al., 2007; Rezaei and Webley, 2010; Gancarczyk et al., 2018).

A final interesting concept within this class of shaped materials is the use of so-called packed foams, where particles are loaded into a metallic foam. In this way, the enhanced heat management can be combined with a high weight of catalyst per unit volume, albeit at increased pressure drop (relative to the foam) (Vervloet et al., 2013; Gascon et al., 2015; Visconti et al., 2016; Balzarotti et al., 2020). This concept can also be applied by using other reactor internals such as corrugated sheets, wire meshes and static mixers, as in principle, any metallic reactor internal can be filled with catalyst particles (Rezaei and Webley, 2010; Kapteijn and Moulijn, 2020).

The reviewed techniques can roughly be divided into two categories; dense randomly packed beds and cellular structures. The division between the two categories is shown qualitatively in Figure 4. The former class has a high catalyst holdup and is therefore the concept of choice for kinetically-limited reactions. However, achieving proper heat management and acceptable pressure drop are generally challenging with this type of packing. The latter class, in contrast, exhibits very low pressure drop and excellent thermal management, which benefits process economics, but the low catalyst content limits application to specific high-throughput applications. For application of cellular structures in kinetically-limited reactions, the reactor would need to be oversized and this would impact the safety aspects of the chemical process. Hence, there is a "sweet spot" of moderate catalyst holdup and tunability in transport properties, the area in the center of Figure 4, that is yet untouched by current shaping methods, but can likely be achieved with structures produced by additive manufacturing techniques. Operating characteristics such as these have the potential to aid many reaction systems, but one should realize that it is not a solution for all reactor engineering challenges. Some processes indeed require a very high catalyst holdup or extremely low pressure drop, and then it is more reasonable to go with more mature conventional shaping technologies rather than the relatively expensive additive manufacturing. In the next section, the additive manufacturing process is discussed and its ability to produce structures within this "sweet spot", and perhaps in other, yet unexplored, operating regimes, is assessed.

\section{MATURE ADDITIVE MANUFACTURING TECHNIQUES FOR CATALYST AND SORBENT MATERIALS}

Additive manufacturing by means of 3D-printing was introduced in a series of research developments and resulting patents in the 1980s and early 1990s (Gupta et al., 2019b). In the decades following these works, the innovations have found their way in a variety of applications, ranging from simple consumer machines for printing household objects (mainly from polymers) to the production of custom components for aerospace applications (mainly from metals) (Nickels, 2015; Ngo et al., 2018). The terms additive manufacturing and 3Dprinting cover a multitude of technologies for the shaping of a variety of materials, which can roughly be divided into three classes: polymers, metals and ceramics. Within the different technologies, the main distinction is between direct and 
indirect shaping methods. The former class of methods contains technologies where material is deposited locally in the amount that is required. In contrast, the latter class features technologies in which layers of material sized to the print surface are present, producing only certain patterns, for example by local sintering, photocuring or application of binder (Guo and Leu, 2013; Zocca et al., 2015). Past works in the field of chemical engineering have seen the utilization of all of the three material classes mentioned. Firstly, one of the most innovative applications is the use of polymers to manufacture (transparent) microflow devices (Kitson et al., 2012; Kitson et al., 2016; Gupta et al., 2019a; Sagandira et al., 2020; Sans, 2020). This is a key utilization of the ability of 3D printing to manufacture one-off components and rapidly prototype without the economy of scale, and the feedstock flexibility allows for the tuning of the chemical inertness to the intended reaction environment (Manzano et al., 2017; Kotz et al., 2019). The widespread use of polymer-based 3D-printers has also led to an increased interest in the technology within educational environments, enabling the production of cheap laboratory equipment, ranging from simple laboratory vessels to microscopes and fully functional distillation columns (Mardani et al., 2016; Collins et al., 2020; Gordeev and Ananikov, 2020). Secondly, AM of metals is successfully utilized in a chemical engineering context for more demanding processes, such as reactors with custom internals (Sun et al., 2018; Zentel et al., 2020) and is proposed as a viable alternative to the just-in-time production of spare parts in the industry (Durão et al., 2017). Finally, in heterogeneous catalysis and structuring of sorbents, the class of ceramic materials is the most appropriate; this will therefore be the main focus of this chapter. This class of materials, however, has as of yet the lowest level of technological maturity in the AM field due to various complexities (Willemsen and De Boer, 2020). To date, the 3D-printing of ceramics has mostly found applications in the medical field, such as the production of custom teeth and bones. This exploits the AM philosophy by using both the level of detail achievable and the possibility of custom components (Zocca et al., 2015). Specifically for the 3Dprinting of ceramics, some additional questions can be asked that set apart the different printing technologies: firstly, can a fully dense product be achieved? secondly, how much ceramic material is present in the initial paste? and thirdly, what is the degree of complexity in the post-processing steps? For a complete overview of the different technologies for AM of ceramics, excellent reviews are available in the literature (Travitzky et al., 2014; Hurt et al., 2017; Chen et al., 2019). Within the framework of 3D-printing of catalysts and sorbents, some constraints limit the choice of an appropriate technology. For example, several AM technologies, such as selective laser melting, locally heat up a powder bed until the melting point (or near the melting point for solid state sintering). For ceramics, this requires very high temperatures (typically higher than $1,000^{\circ} \mathrm{C}$ ), which may alter the catalytic nature of the material. In addition, the melting and solidification steps are likely to have an effect on the (hierarchical) pore structure of the material and its recrystallisation into the desired form (Kruth et al., 2005; Qian and Shen, 2013). With these restrictions in mind, Direct Ink Writing (DIW) and Digital Light Processing (DLP) are considered the technologies with most practical potential. The former technology represents the majority of cases relevant to catalyst structuring in the literature and is relatively mature. Highlighting both technologies allows for an interesting view on two widely different additive manufacturing methods, their benefits and drawbacks. In this section, the two technologies will be introduced with specific focus on the limitations in terms of geometrical freedom and materials that can be used. This is followed by an overview of the possibilities of implementation at the reactor scale. This provides the relevant fundamental context of the different shaping methods to consider the increased process intensification that additive manufacturing may enable.

\subsection{Direct Ink Writing}

DIW is one of the many synonyms that exist for extrusion-based methods, all of which function on the same principle, but with subtle differences (Travitzky et al., 2014). The use of this method for the current purpose historically stems from the cornerstone work of Smay et al. (2002), Lewis (2006) and Lewis et al. (2006). The printing paste for DIW is prepared by mixing catalyst powder with binders, additives and a diluent, similarly to the slurry used in extrusion (Lefevere et al., 2017). The viscous paste is then loaded into the printer and extruded through a nozzle, as shown schematically in Figure 5. The rheological properties, and specifically the viscosity, are critical variables, since it is vital that the paste extrudes properly whilst the structure does not collapse or sag while printing (M’Barki et al., 2017; Chen et al., 2019). To influence these properties, the diluent content is varied (a typical amount would be 10\%) and dispersing agents may be added (Faes et al., 2015). The exact composition generally depends on the properties of the initial powder, which can influence the printability significantly for any AM technology (Shakor et al., 2020; Zhou et al., 2021). For structures printed using DIW, some degree of sagging is often observed, as the freshly printed features weigh down on the rest of the structure and dent the previous layer (Bellini et al., 2005). This effect increases in severity as print time passes and the height of the structure increases. After printing, the structure is dried, possibly debinded, and calcined according to a specific protocol. Performing this postprocessing step in a reliable way has proven a challenge, since the conditions of both drying and calcining should be selected with care to ensure a structure that is mechanically stable and retains its intended geometry (Travitzky et al., 2014; Lefevere et al., 2017).

The design possibilities that can be achieved with extrusionbased methods have some constraints. First of all, the size and shape of the nozzle used dictate the size and shape of the features. Previous works in the literature solely use a circular nozzle, and hence the structural features were cylindrical (this is generally true, variations in printing parameters may result in features that better resemble a rectangular prism). The size of the nozzle is generally between 0.1 and $1.5 \mathrm{~mm}$ (Peng et al., 2018; Lefevere et al., 2018). In the literature, this printing method has mostly been used to produce structures which are described as pseudomonoliths or logpile structures. These structures mostly exist in two basic variations; straight and staggered configurations, as illustrated in Figure 6. The catalyst holdup can be varied by 

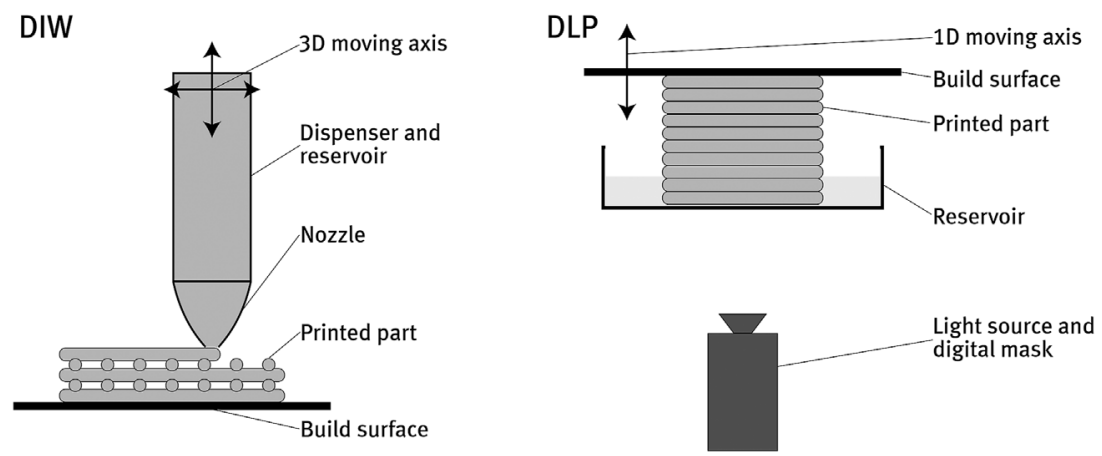

FIGURE 5 | Schematic illustration of additive manufacturing by DIW (left) and DLP (right).

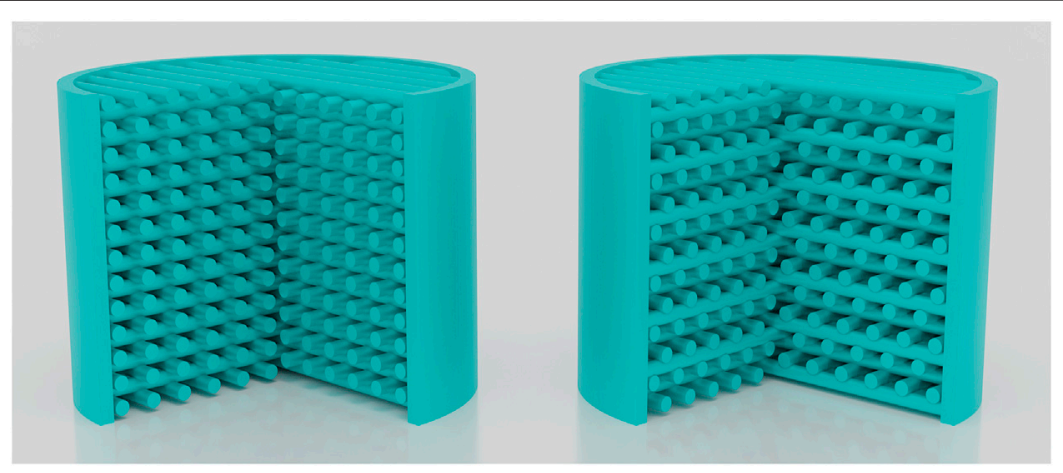

FIGURE 6 | Impression of the two variations of 3D-printed logpile structures, straight on the left side and staggered on the right side.

changing the gap between the cylinders, which generally results in a gas holdup between 50 and $80 \%$, exactly in the "sweet spot" that is hard to achieve with conventional shaping methods (Lefevere et al., 2018). The overall size of the sample may be partially constrained by the aforementioned denting of the structure over time, and to a lesser degree by the build surface of the printer. Most produced samples in the current literature are in the order of centimeters, but it can certainly be hypothesized that larger structures are possible when optimizing the rheological properties; the small size may be due to the proof-of-concept stage of the technology, without any scaleup attempts. It is likely that there is potential for scaling, albeit with a possible loss of printing resolution, thanks to successful developments of ceramic 3D-printing on the meter scale being undertaken in other fields of research (Zocca et al., 2015; Ngo et al., 2018). The degree of shrinkage in the finished product, due to diluent and organic binder removal, is limited as the solid fraction of the 3D-printing paste is fairly high (Chen et al., 2018; Peng et al., 2018). One of the drawbacks of this technology for other applications is its inability to produce fully dense products (Chen et al., 2019). However, specifically for catalyst and sorbent materials, densification during sintering would be detrimental to the pore system and is thus not pursued. The removal of organic binders may introduce some residual porosity and hence it is emphasized that careful consideration of the postprocessing protocol is required to ensure that the finished product is dimensionally accurate and possesses the intended pore structure (Shang et al., 2015; Lefevere et al., 2017).

The printing speed depends on a variety of factors, and is often not stated in the literature. From operating experience at the Flemish Institute for Technological Research, a general guideline is that the printing of centimeter-sized structures through DIW requires tens of minutes to hours. Again, this value only serves as a rough indication for comparative purposes, as printing times may vary across different machines and may be decreased through scale-up progress and higher industrial experience with the technology.

Extrusion methods are generally suitable for a broad range of catalytic and sorbent materials. As will be shown in the next section, in particular the DIW of zeolites and Metal Organic Framework materials (MOFs) has been well researched to date. From a chemical point of view, the printing does not seem to influence the material drastically. As mentioned, some porosity changes are observed for the printed material compared to the initial powder. This, in turn, affects the active surface area of the material. These considerations are largely related to catalyst-binder selection, the challenges of which are no different for $3 \mathrm{D}$-printing than for conventional shaping methods. 


\subsection{Digital Light Processing}

DLP is a stereolithographical method, employing photopolymerization to enable the shaping of material. For application in DLP, the catalyst is mixed with (acrylate) monomers, dimers, oligomers and photoinitiator compounds to form a low-viscosity ink, also called resin. Shaping occurs by local setting of a layer of this ink by the application of UV light through a mask. The light activates the photopolymerization locally, setting a polymeric network and trapping the catalyst inside the intended geometry. The light is guided by the aforementioned mask, which consists of thousands of pixels (Gordeev and Ananikov, 2020). The printing is conducted upside down, meaning that the structure is pulled up layer by layer from the bath of ink, as shown schematically in Figure $\mathbf{5}$ (Zocca et al., 2015). The formulation of the ink has stringent requirements on total content, size and the dispersion of solids, as these properties influence the optical and rheological properties which are important to ensure proper operation of the printer. As a general guideline, a maximum of approximately $60 \%$ solid content in the ink is possible to achieve (An et al., 2017; Varghese et al., 2018; Li H. et al., 2020). During postprocessing, the polymeric network is combusted, which is required since it is not stable at high temperatures, and therefore needs to be removed before use. Whilst this holds for many zeolite catalysts, sorbents do not typically operate at such high temperatures and thus the polymeric matrix does not have to be removed for this application. Removal of the polymeric network is likely to introduce significant shrinkage and additional porosity. In addition, anisotropic shrinkage is reported, i.e. a larger degree of shrinkage along a certain axis (An et al., 2017).

The feature size that can be reached with DLP is governed by the size of the pixels. These are generally a few microns, depending on the printer, but in any case, this is orders-ofmagnitude lower than DIW (Zocca et al., 2015). In the literature, the overall size of the sample is in the order of centimeters. This is comparable to DIW, but it should be noted that DLP print surfaces are generally smaller than DIW-type machines. Operating experience with this technology shows that the printing speed is much lower, and a structure similar to the DIW benchmark structure takes approximately ten times longer to complete. Besides the capability of DLP to yield more complex geometries, an additional advantage that this technology offers in scale-up considerations is that the time required to construct a layer is independent of layer size, as it solely depends on its curing times. This may allow for a more favourable comparison of printing times at larger scales.

Structural design through DLP may be limited by two factors. One constraint in design freedom arises from the fact that the structure is pulled up from the bath of ink. This imposes slight limitations on geometries that can be achieved, as crevices where liquid is trapped inside the structure should be avoided. In addition, samples are reported to be affected by the staircase effect (Ngo et al., 2018; Zimmer et al., 2021). This phenomenon is a result of the layered AM process, and introduces small imperfections, as curved features are always stepped (although developments in the relatively new continuous DLP enable enhanced surface finishing) (Janusziewicz et al., 2016). These limitations are minimal and in the literature, it is seen that DLP is used to produce a far greater variety of structures compared to DIW (Papetti et al., 2018). These are mostly produced from alumina, silica, zirconia or silicon carbide (Chartier et al., 2002; Zakeri et al., 2020; Bai et al., 2021; Sun et al., 2021). Whilst these are potential catalyst support materials, the use of DLP for the shaping of actual catalytic material and application in reactive environments is less widespread in the literature, with some notable studies in activation and liquid phase chemistry (Manzano et al., 2017; Santoliquido et al., 2017; Zhakeyev et al., 2017; Simon and Dimartino, 2019; Wang et al., 2020; Zhang et al., 2020). There are potential limitations on materials when they are influenced by the conditions of the ink, e.g., for photoresin the $\mathrm{pH}$, balance between viscosity and copolymerization and exposure/curing parameters need to be accounted for when selecting solid materials. Since problems of this nature have not yet been fully addressed, it can be concluded that DLP currently suffers from more practical issues than the more mature DIW. However, if these are resolved, current developments demonstrate that the geometrical freedom has good potential for realizing the promise of process intensification.

\subsection{The Reactor Scale}

As mentioned, the field of AM of catalysts is fairly young and hence most developments are on the R\&D lab scale, with centimeter-sized structures. In fact, the initial testing of printed catalyst is often done by crushing printed samples to ensure that the printed powder has maintained similar catalytic activity compared to the original powder (Middelkoop et al., 2019b). For the application of these relatively small structures in industrial processes, two strategies are currently described in the literature. The first is the numbering up of multiple smaller reactor vessels. A strategy similar to this is the use of multitubular reactors in large-scale chemical processes. This reactor configuration is mostly used for reactions with strong heat effects, as heat transfer to the catalytic bed may be limiting in reactor tubes of larger diameter. Conventionally, these tubes are randomly packed with particles. A complication that is often encountered is packing inconsistencies amongst the different tubes that manifest themselves in a maldistribution of the flow caused by differences in pressure drop (Shinnar et al., 1992). One notable benefit that a 3D-printed catalyst may offer is consistency; as the printed structures are identical, the pressure drop over the different tubes is exactly the same and thus the even distribution of reactants is facilitated. An example of this scaling strategy that is perhaps more relevant is the use of numbering up for the scale-up of (photo-catalytic) microflow applications. In recent decades, microflow chemistry has emerged as an efficient way of producing chemicals with multiple step syntheses without the need for separate batch reactors (Mizuno et al., 2016). However, due to the relatively small size of an individual production unit (much like the current size of 3Dprinted catalyst structures), the use of multiple units is required. When scaling up, challenges exist in evenly distributing reactant flows amongst multiple microflow devices, as was the case for large scale multitubular reactors in industry. Some loss may be experienced as the economy of scale does not work one-to-one for 
numbering up, but the concept provides great opportunities for distributed production (Dong et al., 2021).

A second scale-up strategy described by Danaci et al. (2019) is to make a longer vessel and stack multiple $3 \mathrm{D}$-printed structures to fill it. This concept is simple and does not require additional equipment, but care is likely to be required to ensure that the different elements are aligned. The 3D-printing of connector pieces as part of the different elements may aid in this challenge.

Both of these approaches have the potential to live up to the potential of 3D-printing, as structure placement can be consistent which allows for even performance. This is in contrast to a random packing approach commonly used for extrudates and pellets. One key aspect that needs to be taken into account in both approaches is the fact that structures can be quite brittle and that shrinkage may influence the dimensional accuracy, which may give rise to sealing issues upon incorporation in the reactor.

Finally, some caution is necessary when considering the reactor scale, as the current scale of printing is relatively slow and the process requires many manual steps. This is in contrast to an industrial screw extruder or granulation process, which can operate in a more continuous manner. In addition, it is good to take into account other technologies which are currently in development as well as more mature scaling of metallic 3Dprinting, as these potentially enable more facile printing of largescale structures.

\section{APPLICATION OF 3D-PRINTED STRUCTURES IN CHEMICAL PROCESSES AND POTENTIAL PROCESS INTENSIFICATION}

The literature features many works in which formulation and operating parameters are optimized for the 3D-printing of specific materials for application in chemical processes. A large portion of the research scope in these studies is typically dedicated to chemical optimization; looking into morphological changes in the pore system due to the printing and sintering operations, assessing any adverse catalytic influences of binders and establishing whether the printed and post-processed structure is mechanically stable. Often, this is concluded with a proof-of-concept, where the novel geometry is benchmarked against a reference case (often a packed bed or a crushed structure). Before reviewing some of these benchmarking results, it is useful to establish some common reasons for ambiguity in the comparison. This information is vital to take into account, since it may obscure the observed benefits of the 3D-printing technology.

Firstly, it is often seen that 3D-printed structures are compared at constant WHSV or flow rate. This is not necessarily bad practice. However, it should be realized that the gas holdup is often different for 3D-printed structures compared to packed beds, so that a WHSV value does not represent the same residence time in a packed bed as it does in a $3 \mathrm{D}$-printed structure.
Secondly, it should be acknowledged that many 3D-printed structures include a binder. This lowers the amount of catalytic material per mass of solid and the binder material may induce unwanted catalytic effects. This has already been discussed above, but is vital to reiterate, since some works reported in the literature directly compare results of a powder without binder to a $3 \mathrm{D}$ printed structure with binder, without decoupling the effects of 3D printing and inclusion of binder.

Thirdly, it may occur that a reaction is tested which is operated in the internal mass transfer limited regime as a benchmark. The availability of active sites thanks to additional porosity may then strongly impact the reaction rate. On the other hand, binder material may also block existing pore systems, leading to lower accessibility of active sites. In the analysis of the results, macroscopic effects such as improved residence time distribution and mixing behavior have to be decoupled from microscopic effects within the catalytic pore system.

Finally, the authors wish to stress that actual information about operating windows in terms of mixing behavior, dispersion, pressure drop and heat- and mass transfer is not as readily available as for the conventional shaping technologies. Hence, the observed results may be explained by a variety of effects which have yet to be assessed concretely. For example, logpile structures, which are pseudo-monolithic structures, can be expected to exhibit transverse dispersion at an intermediate level between honeycomb monoliths and packed beds, but this cannot be put into quantitative terms with the current information available. Quantitative information is solely available for the gas holdup and solid weight per volume, which is also at an intermediate level between the two model reactor types.

With these considerations in mind, relevant cases can be reviewed. This is done in two sections. The first section summarizes developments where ceramic catalyst is shaped into logpile structures, since these represent the majority of relevant studies in the field. The second section looks beyond this, and considers the structuring of (coated) reactor internals from different materials through the use of AM. Whilst these latter developments may not be directly related to catalysis, and may not succeed in achieving the "sweet spot" of catalyst holdup, process intensification is realized nonetheless. Looking into these concepts can aid in the further exploration of the potential of the shaping technology, and perhaps some of the postulated benefits can be translated to the shaping of catalysts as well.

\subsection{Logpile Structures}

Tables 1, 2 outline some of the highlights of the work pertinent to logpile structures shaped by DIW for catalytic and sorption applications, respectively. Please note that dozens of additional studies exist, of which many are referenced in this work, however from an engineering point of view they are deemed out of the scope of the current highlights. In the text following this table, several cases are further elaborated upon in the assessment of successful process intensification.

Two separate groups, at the University of Santiago de Compostela and Missouri University of Science respectively, are noteworthy for their pioneering work. The work by the 
TABLE 1 | Overview of recent literature studies using catalyst logpile structures produced by DIW.

\begin{tabular}{|c|c|c|c|}
\hline Reference & Catalyst & Process & Reported effects \\
\hline Tubío et al. (2016) & $\mathrm{Cu} / \mathrm{Al}_{2} \mathrm{O}_{3}$ & Ullman reaction & $\begin{array}{l}\text { Good catalytic performance } \\
\text { Good recyclability of catalyst } \\
\text { No leeching of active species }\end{array}$ \\
\hline Azuaje et al. (2017) & $\mathrm{Al}_{2} \mathrm{O}_{3}$ & Heterocyclization reactions & $\begin{array}{l}\text { Increased yield thanks to high porosity and surface-to-volume ratio } \\
\text { High stability under cycled operation }\end{array}$ \\
\hline $\begin{array}{l}\text { Díaz-Marta et al. } \\
\text { (2018) }\end{array}$ & $\mathrm{Cu} / \mathrm{SiO}_{2}$ and $\mathrm{Pd} / \mathrm{SiO}_{2}$ & $\begin{array}{l}\text { Selected multi-catalytic } \\
\text { reactions }\end{array}$ & $\begin{array}{l}\text { Successful functionalization of printed structure with different active metals } \\
\text { Compartmentalization of catalyst } \\
\text { Good recyclability of catalyst } \\
\text { No leeching of active species }\end{array}$ \\
\hline Lefevere et al. (2018) & ZSM-5 & Methanol to olefins & $\begin{array}{l}\text { Increased conversion and stability for a dual binder system } \\
\text { Dependence of conversion and stability on feature size, gas holdup and } \\
\text { configuration } \\
\text { Better performance of staggered structures compared to packed beds }\end{array}$ \\
\hline Magzoub et al. (2019) & Doped ZSM-5 & Methanol to olefins & $\begin{array}{l}\text { Mitigation of coke formation by dopants } \\
\text { Decrease of surface area after shaping }\end{array}$ \\
\hline $\begin{array}{l}\text { Middelkoop et al. } \\
\text { (2019b) }\end{array}$ & $\mathrm{Ni} / \mathrm{Al}_{2} \mathrm{O}_{3}$ & $\mathrm{CO}_{2}$ methanation & $\begin{array}{l}\text { Increased productivity of 3D-printed structures compared to pellets and beads } \\
\text { at equal WHSV. } \\
\text { Increased or similar active surface area of printed samples }\end{array}$ \\
\hline Karsten et al. (2020) & $\mathrm{Mn}-\mathrm{Na}-\mathrm{W} / \mathrm{SiO}_{2}$ & $\begin{array}{l}\text { Oxidative coupling of } \\
\text { methane }\end{array}$ & $\begin{array}{l}\text { Reduced active surface area of printed samples } \\
\text { Similar performance of printed sample compared to powder thanks to } \\
\text { optimized calcination conditions } \\
\text { Conceptualization of a 3D-printed structure incorporating a porous membrane }\end{array}$ \\
\hline Liu et al. (2020) & $\begin{array}{l}\mathrm{MIL}-100(\mathrm{Fe}) / \mathrm{SiO}_{2} \text { and HKUST-1/ } \\
\mathrm{SiO}_{2}\end{array}$ & Wastewater treatment & $\begin{array}{l}\text { Demonstration of surface modification after printing and tuning of MOF content } \\
\text { by structural design } \\
\text { Excellent reusability and long-term stability } \\
\text { Conceptualization of 3D-printed reactive impeller }\end{array}$ \\
\hline Jacquot et al. (2021) & $\begin{array}{l}\text { FeCo and } \mathrm{FePd} \text { on } \mathrm{SiO}_{2} \text { and } \\
\text { graphene oxide }\end{array}$ & Benzyl alcohol oxidation & $\begin{array}{l}\text { Modelling of hydrodynamics in straight logpile configuration } \\
\text { Stacking of structures with different active sites for increased conversion } \\
\text { Increased performance of 3D-printed configuration compared to conventional } \\
\text { reactor types }\end{array}$ \\
\hline
\end{tabular}

University of Santiago de Compostela, and in particular the publications by Tubío et al. (2016) and Díaz-Marta et al. (2018), deserves great attention. In these works, the shaping of copper-based catalysts is investigated. Application of these catalysts is done for different model reactions in the liquid phase, but this is a proof-of-concept for versatility of the catalyst rather than an in-depth reactor engineering study. The developments from a chemical perspective, however, are very relevant. In the two works, various impregnation strategies are employed. Both the wet impregnation of alumina with copper species prior to printing and the activation and impregnation of a silica monolith after printing were attempted. It was shown that both methods of impregnation were successful, and that the active metal was distributed throughout the structure. Whilst the latter method did take significantly longer due to the various steps of post-processing, activation and impregnation, it is an important development for the application of the 3D-printing concept in catalysis; in the first place because impregnation of the shaped body unlocks a larger variety of catalyst holdups compared to washcoating; and secondly, because the ability to apply chemical functionality after printing allows for the production of more generic structures that can be tailored for specific reactions by impregnation. This has the potential to simplify the printing process since structures from only a handful of standard support materials are required to enable the application of dozens of catalysts. In addition, good recyclability and stability of the structures is reported, which is important since the structured catalyst (and the active metal) likely represents a significant portion of the operating costs. A testament to the versatility of these techniques is the multicatalysis concept that relies on the impregnation of the same support material with different active metals, and the stacking of the two catalysts to combine their catalytic action (Díaz-Marta et al., 2018). In a follow-up publication, the compartmentalization concept was enhanced by the use of magnetic nanoparticles that allows for facile separation of the various immobilized catalytic functions (Díaz-Marta et al., 2019). In addition, a polypropylene vial for conducting catalytic tests, 
TABLE 2 | Overview of recent literature studies using sorbent logpile structures produced by DIW.

\begin{tabular}{|c|c|c|c|}
\hline Reference & Sorbent & Process & Reported effects \\
\hline Thakkar et al. (2016) & Zeolite $13 \mathrm{X}$ and $5 \mathrm{~A}$ & $\mathrm{CO}_{2}$ adsorption & $\begin{array}{l}\text { Optimized binder content for increased mechanical strength and adsorption capacity } \\
\text { Relatively narrow RTD in breakthrough experiments }\end{array}$ \\
\hline \multirow[t]{2}{*}{ Couck et al. (2017) } & ZSM-5 & $\begin{array}{l}\mathrm{CO}_{2} \text { and } \mathrm{CH}_{4} \\
\text { adsorption }\end{array}$ & Slightly decreased adsorption capacity due to dilution of active material \\
\hline & & & Narrow RTD in breakthrough experiments \\
\hline Couck et al. (2018) & SAPO-34 & $\mathrm{CO}_{2}$ adsorption & $\begin{array}{l}\text { Slightly decreased adsorption capacity due to dilution of active material } \\
\text { High } \mathrm{CO}_{2} \text { selectivity }\end{array}$ \\
\hline Lim et al. (2019) & HKUST-1 & $\mathrm{CH}_{4}$ adsorption & $\begin{array}{l}\text { Successful binderless shaping } \\
\text { Decreased adsorption capacity compared to powder } \\
\text { Relatively high BET area after printing }\end{array}$ \\
\hline $\begin{array}{l}\text { Middelkoop et al. } \\
\text { (2019a) }\end{array}$ & $\begin{array}{l}\text { Zeolite } 13 X \text { and activated } \\
\text { carbon }\end{array}$ & $\begin{array}{l}\mathrm{CO}_{2} \text { and } \mathrm{H}_{2} \mathrm{~S} \\
\text { adsorption }\end{array}$ & $\begin{array}{l}\text { Slightly lower adsorption capacity for printed structures } \\
\text { Increased adsorption and desorption rates compared to beads }\end{array}$ \\
\hline Regufe et al. (2019) & $\begin{array}{l}\text { Zeolite } 13 X \text { and activated } \\
\text { carbon }\end{array}$ & $\mathrm{CO}_{2}$ adsorption & $\begin{array}{l}\text { Successful application of Joule effect for reactor heating } \\
\text { Tuning of adsorption capacity by changing the composition of the structure }\end{array}$ \\
\hline Thompson et al. (2019) & $\begin{array}{l}\text { Zeolite } 13 X \text { and silver } \\
\text { microflakes }\end{array}$ & $\mathrm{CO}_{2}$ adsorption & $\begin{array}{l}\text { Successful application of multi-material printing using conductive sorbent for local } \\
\text { resistive heating } \\
\text { Demonstration of almost complete desorption by heating }\end{array}$ \\
\hline Wang et al. (2019a) & ZSM-5 & $\mathrm{CO}_{2}$ adsorption & $\begin{array}{l}\text { Excellent mechanical strength without binder thanks to zeolite soldering } \\
\text { High adsorption capacity and narrow RTD compared to pellets and extrudates }\end{array}$ \\
\hline Claessens et al. (2020) & $\mathrm{ZIF-8}$ & Butanol adsorption & $\begin{array}{l}\text { Small channels }(<120 \mu \mathrm{m}) \text { exhibit flow maldistribution, influencing RTD. } \\
\text { Slightly lower adsorption capacity for printed structures } \\
\text { Good stability under cycled operation }\end{array}$ \\
\hline Lawson et al. (2020) & Zeolite 13X & $\mathrm{CO}_{2}$ adsorption & $\begin{array}{l}\text { Increased mass transfer rate thanks to macroporous binder } \\
\text { Optimized flow conditions for various structures }\end{array}$ \\
\hline
\end{tabular}

customized to the size of the structures, was fabricated by 3Dprinting (Díaz-Marta et al., 2020).

Within the same area of study, researchers from the Flemish Institute for Technological Research have brought advances in the field of 3D-printing of catalysts and sorbents, providing a sound basis for potential process intensification. The work of Lefevere et al. $(2017,2018)$ features ZSM-5, a catalyst, shaped by DIW, presenting an illustrative investigation into the influence of binders and geometry on the catalyst activity. It was concluded that a mixture of silica and $\mathrm{AlPO}_{4}$ provides optimal results for methanol to olefins, which was used as test reaction. During single binder experiments, $\mathrm{AlPO}_{4}$ was found to increase performance thanks to the relatively low specific surface area. The stability and catalyst lifetime, however, also decreased and this was compensated for by the addition of silica. Following this optimization, the influence of feature size and configuration was assessed. An increasing fiber diameter was found to correlate with a decrease in performance. In addition, lower gas holdup was found to result in an increase in conversion. It was concluded that the 3D-printed logpile structures with a staggered configuration outperform their straight counterparts, and both 3D-printed structures (with features of $1.5 \mathrm{~mm}$ ) outperformed a conventional packed bed of $2 \mathrm{~mm}$ spheres at equal weights of solid. Whilst the work presented has definitely touched upon the various relevant aspects, it should be noted that the flow rate of (diluted) methanol was constant throughout the experiments. In the context of the different bed configurations investigated, the gas holdup varied and hence, the residence time varied. From the publication, it is unclear if this variation in residence time may contribute to the positive effects observed for the 3D-printed structures. In addition, the described effect of feature size may simply be due to varying internal mass transfer resistances, and further investigation is required to attribute the observed effects to the actual geometry enabled by the 3D-printing technology.

A third experimental effort which has received much attention in the literature is the 3D-printing of zeolites and MOFs for the separation of small molecules. This area of research is well represented in Table 2, and most of these studies show similar effects: a decreased adsorption capacity and a narrow RTD during breakthrough experiments. The former is mostly due to the use of binder, as reported in these studies. The latter may enable process intensification. For detailed discussion, the work of Lawson et al. (2020) is considered. This work considers the use of zeolite $13 \mathrm{X}$ as sorbent for $\mathrm{CO}_{2}$ separation. In tuning the binder composition, it was observed that the use of methylcellulose is an effective way to generate additional porosity after calcining, and that this increased the mass transfer rate. Furthermore, the gas holdup 
was varied by producing structures with a varying number of cells per square inch. A detailed study, combining experiments and a fitting procedure, was then conducted to investigate the effect of structural parameters and superficial velocity on the breakthrough curve. The influence of humidity was also assessed. It was shown that for a high number of cells per square inch, a low superficial velocity is optimal, but that the structures with low density are superior in dynamic adsorption performance. The extensive work, along with a fundamental understanding of phenomena involved leads the way to an $a$ priori design of an optimal structure and is thus exemplary for this field of research.

These developments demonstrate that many hurdles have been overcome and that printing of catalyst or sorbent materials can be done successfully. In addition, a range of reactive applications has been tested, in which comparable structures are often employed. The reported studies, however, also reinforce the conclusion that current research has been largely motivated by considerations from chemistry and materials science rather than reactor engineering. Hence, the added benefit in a process intensification context has not objectively been achieved in the current works.

\subsection{Washcoated and Metal Structures}

One particularly relevant area of research in non-ceramic AM for process intensification is research in which the (supported) catalyst is not a ceramic material, but a metal. Various studies have employed the catalytic effect that metals exhibit at high temperatures to produce so-called selfcatalytic reactors (SCR's). Wei et al. (2020) have conducted an excellent experimental work in which they employed Selective Laser Sintering (SLS) to produce honeycomb monolith SCR's with variations of channel geometry. More specifically, iron, cobalt and nickel alloys were investigated for use in $\mathrm{CO}_{2}$ hydrogenation, Fischer-Tropsch synthesis and dry reforming of methane. All of these yielded promising results, with a performance close to or higher than conventional reactors. From an engineering perspective, it was concluded that the thermal conductivity of these materials was orders-of-magnitude higher than conventional (ceramic) support materials and thus the heat management of the reactor was intensified. In addition, the nickel structure was well able to withstand the high-temperature reaction environment. For the Fischer-Tropsch process specifically, it was shown that selectivity may be steered by the configuration of the structure. However, a critical note needs to be made here as, due to the different porosities, the residence time was not constant throughout the different experiments.

Similar work has been conducted by Agueniou et al. (2021), who washcoated a stainless steel honeycomb monolith (also produced through SLS) with supported nickel catalyst. It was shown that the nickel present in the stainless steel already provided some catalytic activity for dry reforming of methane, but that the addition of the washcoat greatly enhanced conversion. In addition, it was shown that a stainless steel structure enables far better heat management compared to a cordierite structure and that the AM process introduces some surface roughness which positively influences heat transfer rates.
Another work of interest in this context is the catalytic static mixer concept as utilized by Nguyen et al. (2018). In this study, electron beam melting is employed to shape stainless steel into a static mixer geometry. This structure is then coated with either nickel or palladium for application in a hydrogenation reaction. The excellent heat and mass transfer abilities of the concept were demonstrated.

All of these studies were able to successfully produce the metal structures with 3D-printing and quantitatively showed the added benefit of the catalyst geometry. However, the first two structures described are essentially honeycomb monoliths, which can already be created through conventional shaping technologies. It is therefore questionable if the $3 \mathrm{D}$-printing aspect provides much novelty in this regard.

Another concept that has received a lot of attention is that of additively manufactured cellular materials from either ceramic material or metal, to be washcoated with catalyst. This concept is generally reported as Periodic Open Cellular Structures (POCS). These foam-like structures have a highly regular structure, which differentiates them from regular foams with a pore size distribution. Various researchers have looked into this concept, and report the high specific surface area and excellent heat transfer performance at low pressure drop (Klumpp et al., 2014; Bianchi et al., 2016; Busse et al., 2018; Lämmermann et al., 2018; Bracconi et al., 2020; Do et al., 2020). The prime advantage of these structures is the tunability of the these parameters as a function of cell geometry and size. The concept is published under a variety of different names for different foam-like geometries, such as aluminium cubic iso-reticular foams by Bastos Rebelo et al. (2018), periodic cellular ceramics with rotated cube unit cell by Santoliquido et al. (2017) or triple periodic minimal surface packings by Zimmer et al. (2021). None of the aforementioned sources feature reactive application of the structure, but various other researchers have looked into this. Several of these studies and their findings are summarized in Table 3.

The critical note to be made with regard to the studies listed in Table 3 is that the weight of catalyst per volume of reactor is very limited for the washcoat configuration employed, much like the situation for honeycomb monoliths and foams. Whilst this has its inherent disadvantages, many of the studies mentioned do realize significant process intensification. More specifically, the use of modelling to decide upon the ideal structure is reported for several of these applications (Chaparro-Garnica et al., 2020; Hajimirzaee and Doyle, 2020); a consideration which is mostly absent in the studies listed in Tables $\mathbf{1}$ and $\mathbf{2}$. At the same time, these works demonstrate that the highly regular structures with custom unit cells are able to provide quantitative benefits over the more randomly structured foams. This is a direct result of the AM strategy applied. Scale-up is also considered to a larger degree compared to the DIW logpile studies, with structures in the order of tens of centimeters being reported (Lind et al., 2020). This is already in the relevant length scale for applications such as automotive exhaust catalysis and hence, the potential for short-term application is very much present.

A final work of interest that demonstrates the excellent heat transfer characteristics of an AM-structured POCS for a reactive application is that of Fratalocchi et al. (2020). They shaped 
TABLE 3 | Overview of literature studies using coated 3D-printed structures.

\begin{tabular}{|c|c|c|c|}
\hline Reference & $\begin{array}{l}\text { Structure } \\
\text { printed material } \\
\text { washcoat }\end{array}$ & Process & Reported effects \\
\hline Lind et al. (2020) & Cubic cell isoreticular foam $\mathrm{AlSi}_{10} \mathrm{Mg} \mathrm{Pt} / \mathrm{Al}_{2} \mathrm{O}_{3}$ & NO oxidation & $\begin{array}{l}\text { Successful scale-up of printed structure and } \\
\text { impregnation procedure } \\
\text { Increased conversion thanks to intensified heat } \\
\text { transfer }\end{array}$ \\
\hline $\begin{array}{l}\text { Papetti et al. (2018, } \\
\text { 2021) }\end{array}$ & Polyhedral open cell foam Cordierite $\mathrm{Pt} / \gamma-\mathrm{Al}_{2} \mathrm{O}_{3}$ & Automotive exhaust catalysis & $\begin{array}{l}\text { Improved CO conversion on cold start compared to } \\
\text { honeycomb monolith } \\
\text { Demonstration of tunable heat transfer properties as } \\
\text { function of porosity }\end{array}$ \\
\hline $\begin{array}{l}\text { Hajimirzaee and Doyle } \\
\text { (2020) }\end{array}$ & $\begin{array}{l}\text { Logpile-like structures with rotational offset Cordierite } \\
\mathrm{Pd} / \mathrm{Pt} \text { on } \mathrm{Al}_{2} \mathrm{O}_{3} / \mathrm{HY} \text { zeolite with promotors }\end{array}$ & $\mathrm{CH}_{4}$ oxidation & $\begin{array}{l}\text { Improved catalytic activity compared to 3D-printed } \\
\text { honeycomb monolith } \\
\text { Modelling proof of improved turbulence as function of } \\
\text { rotational offset. } \\
\text { Choice of optimal structure by balancing improved } \\
\text { turbulence and pressure drop }\end{array}$ \\
\hline Pellejero et al. (2020) & Logpile-like structure ABS ZIF-8 & $\begin{array}{l}\text { Dimethyl methylphosphonate } \\
\text { adsorption }\end{array}$ & $\begin{array}{l}\text { Optimized procedure for low- } \mathrm{T} \text { deposition of } \mathrm{ZnO} \text { and } \\
\text { subsequent conversion to } \mathrm{ZIF}-8 \\
\text { Relatively high adsorption capacity (normalized for } \\
\text { MOF content) }\end{array}$ \\
\hline Danaci et al. (2018) & Logpile structures Copper and stainless steel $\mathrm{Ni} / \mathrm{Al}_{2} \mathrm{O}_{3}$ & $\mathrm{CO}_{2}$ methanation & $\begin{array}{l}\text { Successful shaping of both metals } \\
\text { More favourable temperature profile compared to } \\
\text { packed bed of spheres }\end{array}$ \\
\hline $\begin{array}{l}\text { Chaparro-Garnica et al. } \\
\text { (2020) }\end{array}$ & Honeycomb-like structures Polymeric resin $\mathrm{CuO} / \mathrm{CeO}_{2}$ & CO-PROx & $\begin{array}{l}\text { Application of structured walls to tune content of } \\
\text { active material } \\
\text { Model-based optimization of active surface area and } \\
\text { availability of active sites } \\
\text { Increased conversion thanks to intense mixing and } \\
\text { enhanced heat transfer }\end{array}$ \\
\hline
\end{tabular}

$\mathrm{AlSi}_{7} \mathrm{Mg}_{0.6}$ by selective laser melting for application as a packed foam for Fischer-Tropsch synthesis. Reactive experiments showed that the performance of the packed foam configuration was comparable to a packed bed of spheres without further internals. In addition, it was shown that the structure provided a level of temperature control that could not be achieved in a packed bed of spheres and presented near-isothermal conditions. In addition, co-printing the reactor wall was shown to greatly enhance the heat transfer properties (Fratalocchi et al., 2021). It was also mentioned that acceptable pressure drop could be achieved by tuning the flow properties. Hence, all aspects of process intensification through the structuring of reactor internals are touched upon in this excellent work.

Apart from the reactive studies mentioned, there has also been much work reported on the shaping of metals to achieve high heat transfer in heat exchanger applications (Hansjosten et al., 2018). The exact performance parameters are out of the scope of this review, but these insights are likely to aid in designing optimal structures for heat transfer, or to be employed in a packed foam-like approach. Other relevant developments are studies where the flexibility and ease-of-use of polymeric AM was used to do detailed hydrodynamics studies on model foams which provided validation data for computational fluid dynamics (Gładyszewski and
Skiborowski, 2018; Bracconi et al., 2019). A good example of this is the work by Kramer et al. (2018), who used ABS cylinders as a model of ceramic or metallic substrates for Steam Methane Reforming and optimized the channel geometry of a monolith-like structure. Developments such as these, where modelling and experimental studies are combined to aid in the conceptualization of tailored operating windows, are key in realizing the process intensification potential of the AM technology.

\section{POTENTIAL FOR INCREASED PROCESS INTENSIFICATION}

It has been shown in the previous section that the $3 \mathrm{D}$-printed structures currently produced in a research context may offer some degree of process intensification, and possibly achieve the previously introduced "sweet spot", but in general these geometries are fairly similar to structures that can be created using conventional methods. Hence, it is questionable whether this small gain is able to justify the cost and complexity added in the production process. It is therefore interesting to provide perspective and outline enabling developments in 3D-printing which maximize the process intensification potential of this 
technology. This section introduces the three most relevant concepts and considers the process intensification that can be achieved.

All of these options would benefit greatly from better scaling perspective, as ultimately, large scale implementation requires large structures. This is not a process intensification principle on its own, but should be considered as an underlying determinant for the successful implementation of any 3D-printing innovation.

\subsection{Binderless Printing}

In the previous section it was advocated that the current studies into 3D-printed catalyst and sorbent structures have an inherent disadvantage over virgin powders, as they are diluted with binder materials. Enabling binderless printing would aid in addressing this obvious limitation, both by enabling a higher productivity per volume and eliminating possible adverse side-reactions promoted by binder materials. Different researchers have already made efforts towards realizing this concept, both in the context of 3Dprinting as in conventional shaping technologies (Xu et al., 2012; Elkoro and Casanova, 2018; Wang S. et al., 2019; Lim et al., 2019; Li Z. et al., 2020; Lawson et al., 2021c). In assessing these results, precaution is required as the developments are often highly specific to a certain catalyst within a specific process. The major reason why protocols are not widely applicable is the fact that the ability of a binderless body to be mechanically stable is determined by the cohesive strength of the powder, the degree of porosity required and the post-processing procedure. In addition, the required mechanical stability also depends on the intended application and the shape of the body (Akhtar et al., 2014; Besser et al., 2017; Xu et al., 2017; Kong et al., 2018). This complex interplay of factors demands for a large amount of research for every single application. Within the 3Dprinting technology, however, it is deemed an essential development. Especially since for kinetically-limited processes, it is important that the catalyst weight per volume of reactor is high to achieve a small footprint of the process, which is desired from the point of view of both process safety and economics. These sort of processes are generally unsuitable for intensified reactor internals such as monoliths and foams, and thus optimization of binderless 3D-printed catalyst structures may enable operation in the "sweet spot"; medium catalyst holdup and ample catalytic material without thermal mismanagement or unacceptably high pressure drop.

\subsection{Local Variations}

Throughout this review, the potential for local catalyst structuring has been mentioned as one of the key advantages of the additive manufacturing technology compared to conventional shaping technologies. However, to the knowledge of these authors, this feature has only been used to provide process intensification in one previous work (Davó-Quiñonero et al., 2019). Without requiring advanced simulations or detailed experiments, it is possible to postulate some advantages of the local structuring of catalyst to introduce porosity profiles.

A starting point would be the consideration of axial porosity profiles. An axial porosity profile can aid in distributing the reaction over the length of the reactor by distributing the amount of catalyst required locally by the reaction, which helps tune the local heat production or consumption rate to the local heat removal or addition rate. Within the current AM technologies for logpile structures, achieving such a profile should not be overly complex; one can simply change the spacing of the gap between the cylinders along the axial coordinate to achieve the desired effect (Chen et al., 2019). One illustrative reaction that would benefit from this potential is the oxidative coupling of methane. This reaction is strongly exothermic and when operated adiabatically, an axial temperature profile emerges with a hot spot of over $1,050^{\circ} \mathrm{C}$ at a reaction temperature of $800^{\circ} \mathrm{C}$ (Cruellas et al., 2019). The conventional solution to address this issue is the use of a multi-tubular configuration immersed in coolant, introducing a fair amount of pressure drop and associated higher cost (Dautzenberg et al., 1992; Raouf et al., 2014; Cruellas et al., 2017; Vandewalle et al., 2019). The use of axial porosity profiles, created by 3D-printing, would provide an interesting solution here. By increasing the porosity at the potential hot spot areas, easier removal of heat is allowed. In addition, the lower amount of catalyst present ensures that the heat released by the reaction is locally lowered. This seems counter intuitive, since process intensification should lead to a high productivity per unit volume, but it can be hypothesized that the productivity benefit of good temperature control more than compensates for the loss of productivity due to a lower catalyst holdup. In addition, the selectivity towards the targeted products is enhanced by the improved temperature control.

Isothermal operation is not the only potential application. Some reaction systems contain different reactions in series with different optimal operating temperatures. To cater for these requirements, an axial porosity profile can be introduced so that a temperature profile is implied to benefit the reaction, without the need for complex heater configurations (Newberger and Kadlec, 1971; Jeong et al., 2021). A similar strategy can be employed for residence time optimization; by changing the porosity along the axial coordinate, the interstitial velocity is varied and this can be applied to tune the residence time in (sections of) the structure. This has been done by DavóQuiñonero et al. (2019). In this work, a 3D-printed template is employed to create an asymmetrical honeycomb monolith with washcoat. By varying the relative sizes of walls and channels, an axial velocity profile is imposed. The active material is copper on ceria, coated on a ceramic support; the oxidation of $\mathrm{CO}$ is used as a test reaction. It is shown that this asymmetrical configuration outperforms its symmetrical counterpart, which is attributed to the manipulation of transport resistances along the axial coordinate.

Radial porosity profiles may provide similar advantages, especially relevant to heat transfer (Borkink and Westerterp, 1994; Das et al., 2018). Further process intensification, however, can be expected from a combination of both. By combining axial and radial porosity profiles to provide certain densified zones, the flow of fluid can effectively be steered. This would provide some potential for the creation of macro-porous baffles. Baffles are reactor internals commonly used to direct the flow and influence residence time distribution, but unwanted side effects are the relatively high pressure drop and the stagnant 
zones that arise as fluid comes to a halt under the baffle (Berner et al., 1984; Li and Kottke, 1998; Dong et al., 2016; Haag et al., 2018). In contrast to dense obstacles (so-called hard baffles) which guide the flow, a hypothetical macro-porous baffle would direct the flow by local densification and the increased pressure drop that this brings. A macro-porous baffle as described would eliminate the stagnant zones by ensuring that the flow can still pass through the densified zone, albeit with a higher pressure drop compared to the channels. The overall pressure drop of a porous baffle configuration is expected to be lower than the hard baffle configuration, as fluid is allowed to flow through the structure (Yang and Hwang, 2003; Kizilaslan et al., 2018). From a process intensification point of view, a reactive baffle without stagnant zones or an unacceptably high pressure drop would open up new operating windows. For one, the flow can be steered to have intense contact with the wall of the reactor vessel, increasing the radial heat transfer and subsequently allowing for better temperature control. A second potential benefit of a crossflow-like operating regime as described would be the enhanced mass transfer in the radial coordinate. This could be applied to membrane reactors, which can suffer from so-called concentration polarization in fixed beds. This phenomenon occurs when the membrane permeation rate exceeds the radial mass transfer rate, which leads to lowering of the apparent concentration difference and the observed rate of permeation (He et al., 1999; Caravella, 2014). This case of external mass transfer limitations is typically addressed by employing a fluidized bed, but the violent interior of the fluidized bed can severely damage the membrane (Arratibel et al., 2018; de Nooijer et al., 2019). Hence, a cross-flow-like operating regime in a packed bed reactor, as hypothetically possible through the local densification of catalyst, would provide an interesting alternative (Ahmed et al., 2012; Akagi et al., 2018). The flexibility of additive manufacturing then conveniently allows for a gap in the baffled structure to accommodate the membrane.

Porosity profiles are not the only conceptualization of local structuring that can be envisioned. Not by spacing features further apart, but by decreasing the size of these features, profiles can be created along the axial coordinate of the reactor. Doing this, or changing the shape of the features, provides a way of tuning the internal mass transfer resistance and hydrodynamics (Nawada et al., 2017). Tuning the mass transfer resistances, both external and internal, along with the kinetic rate (through the amount of catalyst per volume of reactor) adds another dimension of reaction control and is a novel tool in the optimization of selectivity. This concept has been touched upon in the aforementioned publication by DavóQuiñonero et al. (2019), but internal diffusion limitations were not considered here since a washcoat configuration was used.

\subsection{Multi-Material Printing}

One of the true enabling developments for intensified processes through 3D-printing would be the use of multiple materials in a single AM process. This would allow for multiple catalysts or sorbent materials within a structure. The compartmentalization of these species is likely to benefit multi-step processes which require multiple catalysts for different chemical actions. A basic variation of this concept was already introduced in the work of Díaz-Marta et al. (2018), where DIW logpile structures were impregnated post-printing with different active metals to provide different chemical functionalities. This, however, is a strategy that can also be achieved with conventionally shaped bodies and cannot be considered multi-material printing (Jeong et al., 2021; Martínez et al., 2021). Another possibility would be to mix catalyst and sorbent powders in a desired ratio into the formulation that is loaded into the printer (likely with a decent amount of binder material). This material, when shaped and calcined, can be useful as active sites and sorbent are dispersed very homogeneously throughout the reactor (Martavaltzi and Lemonidou, 2010). This strategy has been employed by Lawson et al. (2021a). In their work, metal-doped CaO/ZSM-5 logpile structures are produced via DIW and utilized for the oxidative dehydrogenation of ethane (using $\mathrm{CO}_{2}$ as oxidant). It was shown that crack-free operation is possible and that an exceptionally high ethylene yield can be achieved, illustrating the potential for the combined structuring of catalyst and sorbent material. A similar strategy can be hypothesized to provide intensified heating. This concept employs magnetic particles incorporated within the catalyst formulation. Through induction, these particles can be heated to provide localized heating and potentially diminish undesired temperature profiles along the reactor (Ceylan et al., 2011; Wang W. et al., 2019; Yassine et al., 2020; Scarfiello et al., 2021). However, both of these process intensification concepts, based on the mixing of several components into the catalyst formulation, are not a unique advantage of the additive manufacturing process. These strategies can be applied to conventional methods as well. Actual additive manufacturing of multiple polymeric or metallic materials within one printing process has been reported, but for ceramic materials this is still considered as one of the holy grails of the field (Vaezi et al., 2013; Hofmann et al., 2014; Zocca et al., 2015; Bandyopadhyay and Heer, 2018; Kowsari et al., 2018). This is mostly due to the mismatches in post-processing conditions and associated shrinkage. As has been stated above, optimizing the printing and post-processing protocols for the shaping of a single ceramic material is complex, and hence it can be expected that this complexity is further increased when attempting to combine different materials within one printing process. One successful application of this concept was already reported in Table 2 . In this study, Thompson et al. (2019) used DIW with dual extruders to produce a sorbent structure with integrated heating. The key to the success of this example is the similarity of the two inks, as the conductive ink (used for resistive heating) was produced by adding silver microflakes to the sorbent formulation. In addition, the postprocessing protocol consisted solely of drying at room temperature, which is mild enough to prevent cracking and similar issues. One promising alternative to true multimaterial printing is the subsequent printing of different materials, and cosintering of these to make the finished part. This, as stated, does require thorough consideration of relevant conditions and shrinkage effects (Raynaud et al., 2020, 2021).

If and when multi-material printing of defect-free, dimensionally accurate structures is possible, the potential of 
additive manufacturing can be more successfully exploited. From a chemical perspective, the aforementioned use of multiple catalysts or sorbent material has obvious advantages, as consistent packing of multiple types of particles is not straightforward (Berger et al., 2002; van Herk et al., 2009). In addition, AM allows for the realization of gradients of active sites along the reactor coordinates to cater for the requirements of a reaction, which is practically impossible for randomly packed reactors.

The possibilities of multi-material printing should not be limited to different catalysts or sorbent materials alone. It could, for example, also be beneficial to incorporate ceramic materials of different porosities into the same vessel. This would enable the printing of a porous membrane within a catalytic structure, ensuring that the membrane is located ideally and diminishing complexity when assembling the reactor. An obvious addition to this would be the printing of dense ceramics as reactor walls, abating sealing issues. The walls could then be printed with inlet connectors at various positions, to allow for a chemical process with staged injection. Finally, features could even be designed to enable different processing routes depending on the inlet conditions. An example of this would be a valve-like structure which stays open at low flow rates and shuts, redirecting the flow, at higher flow rates. Hu et al. (2020) have demonstrated a similar concept using a temperature-responsive hydrogel which swells or collapses as a function of temperature, guiding the product flow to either the outlet or the waste by blocking of either channel.

In this context, ceramic materials are not the most obvious candidates due to their generally low thermal conductivity. Metals are more promising, and their use is more widespread. Regarding foams and honeycomb monoliths, it was already shown that significantly improved thermal management can be realized by using a metal structure. Hence, multi-material printing could potentially serve to provide even more process intensification if the joint printing of metal and ceramic is possible. It was already shown by several researchers that in the POCS concept, heat transfer be could significantly improved by printing the wall attached to the structure. This is the case as a loaded structure features structure-wall point contacts with relatively low conductivity (Bianchi et al., 2012; Busse et al., 2018; Kramer et al., 2018; Fratalocchi et al., 2021). This exemplifies the opportunities of the printing of whole reactors with multiple materials. Heat transfer may be optimized by the use of different materials, internals such as porous membranes can be integrated with ease and there are virtually no sealing issues when the printing and post-processing is done adequately. This concept has great potential for novel applications featuring modular reactors.

\section{CONCLUSION}

The structuring of catalytic reactor internals to tailor operating windows can be achieved by a variety of shaping methods. In this review, it was shown that current shaping technologies produce either very open or very dense structures, but are often not able to achieve a "sweet spot" of medium catalyst holdup and intensified reactor performance. Additive manufacturing of catalytic or sorbent materials certainly has the potential to reach this "sweet spot" and be transformational in process intensification. Applications of the technology have thus far mostly been focused on optimization of the aspects related to chemistry and materials science. This is done with structures that are quite similar to conventionally shaped catalyst bodies. Therefore, proof of additional process intensification by utilization of AM is often lacking. It is indicated that three enabling developments can be applied to realize further process intensification: i) the production of mechanically stable structures without binders; ii) the introduction of local variations throughout the structure; and iii) the use of multiple materials within one printed structure.

From a general point of view, the current implementation of $\mathrm{AM}$ in the field of chemical engineering follows the conventional development of catalytic processes, which is quite linear. First, a large library of materials is tested for their activity in ideal (often diluted), isothermal conditions for activity in a certain chemical process. The optimal material is then selected and tested at increasingly larger scales and shaping is considered. When approaching the industrial scale, reactor engineering considerations such as mixing behavior, heat and mass transfer and pressure drop come into play. Because of these effects, it is very likely that the catalyst is no longer operated at its initial testing conditions. Hence, in hindsight, it would be beneficial to take effects such as these into account at an earlier stage. It is vital that the surge of AM in the field of catalyst and sorbent shaping incorporates these insights and includes process intensification as a primary consideration in its implementation.

\section{AUTHOR CONTRIBUTIONS}

LR wrote the original manuscript and developed the artwork. The main conceptual ideas were drawn from discussions between LR, VM, HW, IR, and MV individually. The final draft was corrected by VM, HW, IR, and MV. All authors contributed to the article and approved the submitted version.

\section{FUNDING}

This article is based on research undertaken in relation to a project (ZEOCAT-3D) which has received funding from the European Union's Horizon 2020 research and innovation programme, under grant agreement No 814548. The authors would like to thank the EU Horizon 2020 programme for this opportunity. This publication only reflects the author's views and neither the funding Agency nor the European Commission are responsible for any use that may be made of the information contained therein. 


\section{REFERENCES}

Afandizadeh, S., and Foumeny, E. A. (2001). Design of Packed Bed Reactors: Guides to Catalyst Shape, Size, and Loading Selection. Appl. Therm. Eng. 21, 669-682. doi:10.1016/S1359-4311(00)00072-7

Agrawaal, H., and Thompson, J. E. (2021). Additive Manufacturing (3D Printing) for Analytical Chemistry. Talanta Open 3, 100036. doi:10.1016/j.talo.2021. 100036

Agueniou, F., Vidal, H., de Dios López, J., Hernández-Garrido, J. C., Cauqui, M. A., Botana, F. J., et al. (2021). 3D-printing of Metallic Honeycomb Monoliths as a Doorway to a New Generation of Catalytic Devices: the Ni-Based Catalysts in Methane Dry Reforming Showcase. Catal. Commun. 148, 106181. doi:10.1016/ j.catcom.2020.106181

Ahmed, S., Seraji, M. T., Jahedi, J., and Hashib, M. A. (2012). Application of CFD for Simulation of a Baffled Tubular Membrane. Chem. Eng. Res. Des. 90, 600-608. doi:10.1016/j.cherd.2011.08.024

Akagi, T., Horie, T., Masuda, H., Matsuda, K., Matsumoto, H., Ohmura, N., et al. (2018). Improvement of Separation Performance by Fluid Motion in the Membrane Module with a Helical Baffle. Separat. Purif. Technol. 198, 52-59. doi:10.1016/j.seppur.2017.07.012

Akhtar, F., Andersson, L., Ogunwumi, S., Hedin, N., and Bergström, L. (2014). Structuring Adsorbents and Catalysts by Processing of Porous Powders. J. Eur. Ceram. Soc. 34, 1643-1666. doi:10.1016/j.jeurceramsoc.2014.01.008

Allen, K. G., von Backström, T. W., and Kröger, D. G. (2013). Packed Bed Pressure Drop Dependence on Particle Shape, Size Distribution, Packing Arrangement and Roughness. Powder Technol. 246, 590-600. doi:10.1016/j.powtec.2013. 06.022

An, D., Li, H., Xie, Z., Zhu, T., Luo, X., Shen, Z., et al. (2017). Additive Manufacturing and Characterization of Complex Al2O3 Parts Based on a Novel Stereolithography Method. Int. J. Appl. Ceram. Technol. 14, 836-844. doi:10.1111/ijac.12721

Arab, S., Commenge, J.-M., Portha, J.-F., and Falk, L. (2014). Methanol Synthesis from $\mathrm{CO} 2$ and $\mathrm{H} 2$ in Multi-Tubular Fixed-Bed Reactor and Multi-Tubular Reactor Filled with Monoliths. Chem. Eng. Res. Des. 92, 2598-2608. doi:10. 1016/j.cherd.2014.03.009

Arratibel, A., Medrano, J. A., Melendez, J., Pacheco Tanaka, D. A., van Sint Annaland, M., and Gallucci, F. (2018). Attrition-resistant Membranes for Fluidized-Bed Membrane Reactors: Double-Skin Membranes. J. Membr. Sci. 563, 419-426. doi:10.1016/j.memsci.2018.06.012

Azuaje, J., Tubío, C. R., Escalante, L., Gómez, M., Guitián, F., Coelho, A., et al. (2017). An Efficient and Recyclable 3D Printed a-Al2O3 Catalyst for the Multicomponent Assembly of Bioactive Heterocycles. Appl. Catal. A: Gen. 530, 203-210. doi:10.1016/j.apcata.2016.11.031

Bai, X., Ding, G., Zhang, K., Wang, W., Zhou, N., Fang, D., et al. (2021). Stereolithography Additive Manufacturing and Sintering Approaches of SiC Ceramics. Open Ceramics 5, 100046. doi:10.1016/j.oceram.2020.100046

Balzarotti, R., Ambrosetti, M., Beretta, A., Groppi, G., and Tronconi, E. (2020). Investigation of Packed Conductive Foams as a Novel Reactor Configuration for Methane Steam Reforming. Chem. Eng. J. 391, 123494. doi:10.1016/j.cej. 2019.123494

Bandyopadhyay, A., and Heer, B. (2018). Additive Manufacturing of MultiMaterial Structures. Mater. Sci. Eng. R: Rep. 129, 1-16. doi:10.1016/j.mser. 2018.04.001

Bara, J. E., Hawkins, C. I., Neuberger, D. T., and Poppell, S. W. (2013). 3D Printing for CO2 Capture and Chemical Engineering Design. Nanomater. Energ. 2, 235-243. doi:10.1680/nme/13.00021

Barelli, L., Bidini, G., Gallorini, F., and Servili, S. (2008). Hydrogen Production through Sorption-Enhanced Steam Methane Reforming and Membrane Technology: A Review. Energy 33, 554-570. doi:10.1016/j.energy.2007.10.018

Barnard, J. A. (1985). "Chapter 2 Types of Ideal Reactor," in Kinetics and Chemical Technology. Vol. 23 of Comprehensive Chemical Kinetics. Editors C. Bamford, C. Tipper, and R. Compton (Amsterdam, Netherlands: Elsevier), 47-111. doi:10.1016/s0069-8040(08)70144-4

Bastos Rebelo, N. F., Andreassen, K. A., Suarez Ríos, L. I., Piquero Camblor, J. C., Zander, H.-J., and Grande, C. A. (2018). Pressure Drop and Heat Transfer Properties of Cubic Iso-Reticular Foams. Chem. Eng. Process. - Process Intensification 127, 36-42. doi:10.1016/j.cep.2018.03.008
Bazmi, M., Hashemabadi, S. H., and Bayat, M. (2013). Extrudate Trilobe Catalysts and Loading Effects on Pressure Drop and Dynamic Liquid Holdup in Porous Media of Trickle Bed Reactors. Transp Porous Med. 99, 535-553. doi:10.1007/ s11242-013-0199-x

Bellefon, C. (2002). "Mass Transfer Limitations: A Bottleneck for High Throughput Screening in Multiphase Catalysis," in Principles and Methods for Accelerated Catalyst Design and Testing. Editors E. G. Derouane, V. Parmon, F. Lemos, and F. R. Ribeiro (Dordrecht: Springer), 71-83. doi:10.1007/978-94-010-0554-8_3

Bellini, A., Shor, L., and Guceri, S. I. (2005). New Developments in Fused Deposition Modeling of Ceramics. Rapid Prototyping J. 11, 214-220. doi:10. 1108/13552540510612901

Berger, R. J., Pérez-Ramı'rez, J., Kapteijn, F., and Moulijn, J. A. (2002). Catalyst Performance Testing. Appl. Catal. A: Gen. 227, 321-333. doi:10.1016/s0926$860 x(01) 00950-4$

Berner, C., Durst, F., and McEligot, D. M. (1984). Flow Around Baffles. J. Heat Transfer 106, 743-749. doi:10.1115/1.3246747

Besser, B., Häuser, L., Butzke, L., Kroll, S., and Rezwan, K. (2017). Straightforward Processing Route for the Fabrication of Robust Hierarchical Zeolite Structures. ACS Omega 2, 6337-6348. doi:10.1021/acsomega.7b00972

Bianchi, E., Heidig, T., Visconti, C. G., Groppi, G., Freund, H., and Tronconi, E. (2012). An Appraisal of the Heat Transfer Properties of Metallic Open-Cell Foams for Strongly Exo-/endo-Thermic Catalytic Processes in Tubular Reactors. Chem. Eng. J. 198-199, 512-528. doi:10.1016/j.cej.2012.05.045

Bianchi, E., Schwieger, W., and Freund, H. (2016). Assessment of Periodic Open Cellular Structures for Enhanced Heat Conduction in Catalytic Fixed-Bed Reactors. Adv. Eng. Mater. 18, 608-614. doi:10.1002/adem.201500356

Bingre, R., Louis, B., and Nguyen, P. (2018). An Overview on Zeolite Shaping Technology and Solutions to Overcome Diffusion Limitations. Catalysts 8, 163. doi: $10.3390 /$ catal 8040163

Boger, T., Heibel, A. K., and Sorensen, C. M. (2004). Monolithic Catalysts for the Chemical Industry. Ind. Eng. Chem. Res. 43, 4602-4611. doi:10.1021/ie030730q

Borght, K., Toch, K., Galvita, V., Thybaut, J., and Marin, G. (2015). Informationdriven Catalyst Design Based on High-Throughput Intrinsic Kinetics. Catalysts 5, 1948-1968. doi:10.3390/catal5041948

Borkink, J. G. H., and Westerterp, K. R. (1994). Significance of the Radial Porosity Profile for the Description of Heat Transport in wall-cooled Packed Beds. Chem. Eng. Sci. 49, 863-876. doi:10.1016/0009-2509(94)80023-5

Bracconi, M., Ambrosetti, M., Maestri, M., Groppi, G., and Tronconi, E. (2020). Analysis of the Effective thermal Conductivity of Isotropic and Anisotropic Periodic Open Cellular Structures for the Intensification of Catalytic Processes. Chem. Eng. Process. - Process Intensification 158, 108169. doi:10.1016/j.cep. 2020.108169

Bracconi, M., Ambrosetti, M., Okafor, O., Sans, V., Zhang, X., Ou, X., et al. (2019). Investigation of Pressure Drop in 3D Replicated Open-Cell Foams: Coupling CFD with Experimental Data on Additively Manufactured Foams. Chem. Eng. J. 377, 120123. doi:10.1016/j.cej.2018.10.060

Busse, C., Freund, H., and Schwieger, W. (2018). Intensification of Heat Transfer in Catalytic Reactors by Additively Manufactured Periodic Open Cellular Structures (POCS). Chem. Eng. Process. - Process Intensification 124, 199-214. doi:10.1016/j.cep.2018.01.023

Butensky, M., and Hyman, D. (1971). Rotary Drum Granulation. An Experimental Study of the Factors Affecting Granule Size. Ind. Eng. Chem. Fund. 10, 212-219. doi:10.1021/i160038a005

Caravella, A. (2014). "Concentration Polarization in Gas Separation," in Encyclopedia of Membranes. Editors E. Drioli and L. Giorno (Berlin: Springer), 1-2. doi:10.1007/978-3-642-40872-4_1641-1

Ceylan, S., Coutable, L., Wegner, J., and Kirschning, A. (2011). Inductive Heating with Magnetic Materials inside Flow Reactors. Chem. Eur. J. 17, 1884-1893. doi:10.1002/chem.201002291

Chaparro-Garnica, C. Y., Jordá-Faus, P., Bailón-García, E., Ocampo-Pérez, R., Aguilar-Madera, C. G., Davó-Quiñonero, A., et al. (2020). Customizable Heterogeneous Catalysts: Nonchanneled Advanced Monolithic Supports Manufactured by 3D-Printing for Improved Active Phase Coating Performance. ACS Appl. Mater. Inter. 12, 54573-54584. doi:10.1021/acsami. 0c14703

Chartier, T., Chaput, C., Doreau, F., and Loiseau, M. (2002). Stereolithography of Structural Complex Ceramic Parts. J. Mater. Sci. 37, 3141-3147. doi:10.1023/a: 1016102210277 
Chen, H., Wang, X., Xue, F., Huang, Y., Zhou, K., and Zhang, D. (2018). 3D Printing of SiC Ceramic: Direct Ink Writing with a Solution of Preceramic Polymers. J. Eur. Ceram. Soc. 38, 5294-5300. doi:10.1016/j.jeurceramsoc.2018. 08.009

Chen, Z., Li, Z., Li, J., Liu, C., Lao, C., Fu, Y., et al. (2019). 3D Printing of Ceramics: A Review. J. Eur. Ceram. Soc. 39, 661-687. doi:10.1016/j.jeurceramsoc.2018. 11.013

Cheng, S.-H., Chang, H., Chen, Y.-H., Chen, H.-J., Chao, Y.-K., and Liao, Y.-H. (2010). Computational Fluid Dynamics-Based Multiobjective Optimization for Catalyst Design. Ind. Eng. Chem. Res. 49, 11079-11086. doi:10.1021/ie1001839

Choudhary, V. R., Sivadinarayana, C., and Mantri, K. (1999). Influence of Catalyst Binder on the Acidity and Activity/selectivity of Ga/H-ZSM-5 Zeolite in Propane Aromatization. J. Chem. Sci. 111, 669-676. doi:10.1007/bf02869122

Claessens, B., Dubois, N., Lefevere, J., Mullens, S., Cousin-Saint-Remi, J., and Denayer, J. F. M. (2020). 3D-Printed ZIF-8 Monoliths for Biobutanol Recovery. Ind. Eng. Chem. Res. 59, 8813-8824. doi:10.1021/acs.iecr.0c00453

Collins, J. T., Knapper, J., Stirling, J., Mduda, J., Mkindi, C., Mayagaya, V., et al. (2020). Robotic Microscopy for Everyone: the OpenFlexure Microscope. Biomed. Opt. Express 11, 2447-2460. doi:10.1364/boe.385729

Colombo, P. (2006). Conventional and Novel Processing Methods for Cellular Ceramics. Phil. Trans. R. Soc. A. 364, 109-124. doi:10.1098/rsta.2005.1683

Couck, S., Cousin-Saint-Remi, J., Van der Perre, S., Baron, G. V., Minas, C., Ruch, P., et al. (2018). 3D-printed SAPO-34 Monoliths for Gas Separation. Microporous Mesoporous Mater. 255, 185-191. doi:10.1016/j.micromeso. 2017.07.014

Couck, S., Lefevere, J., Mullens, S., Protasova, L., Meynen, V., Desmet, G., et al. (2017). CO2, CH4 and N2 Separation with a 3DFD-Printed ZSM-5 Monolith. Chem. Eng. J. 308, 719-726. doi:10.1016/j.cej.2016.09.046

Cruellas, A., Melchiori, T., Gallucci, F., and van Sint Annaland, M. (2017). Advanced Reactor Concepts for Oxidative Coupling of Methane. Catal. Rev. 59, 234-294. doi:10.1080/01614940.2017.1348085

Cruellas, A., Melchiori, T., Gallucci, F., and van Sint Annaland, M. (2019). Oxidative Coupling of Methane: A Comparison of Different Reactor Configurations. Energy Technol. 8, 1900148. doi:10.1002/ente.201900148

[Dataset] Bazer-Bachi, F., Haroun, Y., Digne, M., and Le Corre, V. (2014). Helical Extrusion of Asymmetric Multilobe Catalyst Supports. EP2886194A1. Munich: European Patent Office.

[Dataset] Bambrick, W. E. (1986). Improved Shape for Extruded Catalyst Support Particles and Catalysts. EP86113184A1. Munich: European Patent Office.

Danaci, S., Protasova, L., Middelkoop, V., Ray, N., Jouve, M., Bengaouer, A., et al. (2019). Scaling up of 3D Printed and Ni/Al2O3 Coated Reactors for CO2 Methanation. React. Chem. Eng. 4, 1318-1330. doi:10.1039/c9re00092e

Danaci, S., Protasova, L., Snijkers, F., Bouwen, W., Bengaouer, A., and Marty, P. (2018). Innovative 3D-Manufacture of Structured Copper Supports post-coated with Catalytic Material for $\mathrm{CO} 2$ Methanation. Chem. Eng. Process. - Process Intensification 127, 168-177. doi:10.1016/j.cep.2018.03.023

Das, S., Deen, N. G., and Kuipers, J. A. M. (2018). Multiscale Modeling of FixedBed Reactors with Porous (Open-cell Foam) Non-spherical Particles: Hydrodynamics. Chem. Eng. J. 334, 741-759. doi:10.1016/j.cej.2017.10.047

Dautzenberg, F. M., Schlatter, J. C., Fox, J. M., Rostrup-Nielsen, J. R., and Christiansen, L. J. (1992). Catalyst and Reactor Requirements for the Oxidative Coupling of Methane. Catal. Today 13, 503-509. doi:10.1016/ 0920-5861(92)80071-t

Davó-Quiñonero, A., Sorolla-Rosario, D., Bailón-García, E., Lozano-Castelló, D., and Bueno-López, A. (2019). Improved Asymmetrical Honeycomb Monolith Catalyst Prepared Using a 3D Printed Template. J. Hazard. Mater. 368, 638-643. doi:10.1016/j.jhazmat.2019.01.092

Derouane, E. G., Lemos, F., Corma, A., and Ribeiro, F. R. (2000). Combinatorial Catalysis and High Throughput Catalyst Design and Testing. Dordrecht: Springer.

Díaz-Marta, A. S., Yañez, S., Lasorsa, E., Pacheco, P., Tubío, C. R., Rivas, J., et al. (2020). Integrating Reactors and Catalysts through Three-Dimensional Printing: Efficiency and Reusability of an Impregnated Palladium on Silica Monolith in Sonogashira and Suzuki Reactions. ChemCatChem 12, 1762-1771. doi:10.1002/cctc. 201902143

Díaz-Marta, A. S., Tubío, C. R., Carbajales, C., Fernández, C., Escalante, L., Sotelo, E., et al. (2018). Three-Dimensional Printing in Catalysis: Combining 3D Heterogeneous Copper and Palladium Catalysts for Multicatalytic
Multicomponent Reactions. ACS Catal. 8, 392-404. doi:10.1021/acscatal. $7 \mathrm{~b} 02592$

Dietrich, B. (2012). Pressure Drop Correlation for Ceramic and Metal Sponges. Chem. Eng. Sci. 74, 192-199. doi:10.1016/j.ces.2012.02.047

Do, G., Geißelbrecht, M., Schwieger, W., and Freund, H. (2020). Additive Manufacturing of Interpenetrating Periodic Open Cellular Structures (interPOCS) with in Operando Adjustable Flow Characteristics. Chem. Eng. Process. - Process Intensification 148, 107786. doi:10.1016/j.cep.2019.107786

Dong, J., Hu, B., Pacek, A. W., Yang, X., and Miles, N. J. (2016). The Effect of Bottom Shape and Baffle Length on the Flow Field in Stirred Tanks in Turbulent and Transitional Flow. Int. J. Mech. Mechatronics Eng. 10, 1651-1660. doi:10.5281/zenodo.1126537

Dong, Z., Wen, Z., Zhao, F., Kuhn, S., and Noël, T. (2021). Scale-up of Micro- and Milli-Reactors: An Overview of Strategies, Design Principles and Applications. Chem. Eng. Sci. X 10, 100097. doi:10.1016/j.cesx.2021.100097

Duan, Y., Xu, M., Zhou, X., and Huai, X. (2014). A Structured Packed-Bed Reactor Designed for Exothermic Hydrogenation of Acetone. Particuology 17, 125-130. doi:10.1016/j.partic.2013.07.010

Dukhan, N., Bağcl, Ö., and Özdemir, M. (2014). Metal Foam Hydrodynamics: Flow Regimes from Pre-darcy to Turbulent. Int. J. Heat Mass Transfer 77, 114-123. doi:10.1016/j.ijheatmasstransfer.2014.05.017

Durão, L. F. C. S., Christ, A., Zancul, E., Anderl, R., and Schützer, K. (2017). Additive Manufacturing Scenarios for Distributed Production of Spare Parts. Int. J. Adv. Manuf Technol. 93, 869-880. doi:10.1007/s00170-0170555-z

[Dataset] Ebner, J. R., and Keppel, R. A. (1991). Shaped Oxidation Catalyst Structures for the Production of Maleic Anhydride. EP0552287B1. Munich: European Patent Office.

Elkoro, A., and Casanova, I. (2018). 3D Printing of Structured Nanotitania Catalysts: A Novel Binder-free and Low-Temperature Chemical Sintering Method. 3D Printing and Additive Manufacturing 5, 220-226. doi:10.1089/ 3dp.2017.0164

Ergun, S. (1952). Fluid Flow through Packed Columns. Chem. Eng. Prog. 48, 89-94.

Etchells, J. C. (2005). Process Intensification. Process Saf. Environ. Prot. 83, 85-89. doi:10.1205/psep.04241

Ewsuk, K. G. (2001). "Powder Granulation and Compaction," in Encyclopedia of Materials: Science and Technology. Editors K. Buschow, M. Flemings, E. Kramer, P. Veyssière, R. Cahn, B. Ilschner, et al. (Amsterdam: Elsevier), 7788-7800. doi:10.1016/b0-08-043152-6/01401-7

Faes, M., Valkenaers, H., Vogeler, F., Vleugels, J., and Ferraris, E. (2015). Extrusion-based 3D Printing of Ceramic Components. Proced. CIRP 28, 76-81. doi:10.1016/j.procir.2015.04.028

Fougerit, J. M., Gnep, N. S., Guisnet, M., Amigues, P., Duplan, J. L., and Hugues, F. (1994). Effect of the Binder on the Properties of a Mordenite Catalyst for the Selective Conversion of Methanol into Light Olefins. Stud. Surf. Sci. Catal. 84, 1723-1730. doi:10.1016/s0167-2991(08)63725-8

Fratalocchi, L., Groppi, G., Visconti, C. G., Lietti, L., and Tronconi, E. (2020). Adoption of 3D Printed Highly Conductive Periodic Open Cellular Structures as an Effective Solution to Enhance the Heat Transfer Performances of Compact Fischer-Tropsch Fixed-Bed Reactors. Chem. Eng. J. 386, 123988. doi:10.1016/j.cej.2019.123988

Fratalocchi, L., Groppi, G., Visconti, C. G., Lietti, L., and Tronconi, E. (2022). Packed-POCS with Skin: A Novel Concept for the Intensification of Nonadiabatic Catalytic Processes Demonstrated in the Case of the Fischer-Tropsch Synthesis. Catal. Today 383, 15-20. in press. doi:10.1016/j.cattod.2020.12.031

Friend, C. M., and Xu, B. (2017). Heterogeneous Catalysis: A central Science for a Sustainable Future. Acc. Chem. Res. 50, 517-521. doi:10.1021/acs.accounts. $6 \mathrm{~b} 00510$

Gancarczyk, A., Iwaniszyn, M., Piątek, M., Korpyś, M., Sindera, K., Jodłowski, P. J., et al. (2018). Catalytic Combustion of Low-Concentration Methane on Structured Catalyst Supports. Ind. Eng. Chem. Res. 57, 10281-10291. doi:10. 1021/acs.iecr.8b01987

Gancarczyk, A., Sindera, K., Iwaniszyn, M., Piątek, M., Macek, W., Jodłowski, P. J., et al. (2019). Metal Foams as Novel Catalyst Support in Environmental Processes. Catalysts 9, 587. doi:10.3390/catal9070587

Gascon, J., Van Ommen, J. R., Moulijn, J. A., and Kapteijn, F. (2015). Structuring Catalyst and Reactor - an Inviting Avenue to Process Intensification. Catal. Sci. Technol. 5, 807-817. doi:10.1039/c4cy01406e 
George, G. R., Bockelmann, M., Schmalhorst, L., Beton, D., Gerstle, A., Torkuhl, L., et al. (2021). Workflow for Computational Fluid Dynamics Modeling of Fixedbed Reactors Packed with Metal Foam Pellets: Hydrodynamics. Aiche J. e17284, 1-15. doi:10.1002/aic.17284

Giani, L., Groppi, G., and Tronconi, E. (2005a). Heat Transfer Characterization of Metallic Foams. Ind. Eng. Chem. Res. 44, 9078-9085. doi:10.1021/ie050598p

Giani, L., Groppi, G., and Tronconi, E. (2005b). Mass-Transfer Characterization of Metallic Foams as Supports for Structured Catalysts. Ind. Eng. Chem. Res. 44, 4993-5002. doi:10.1021/ie0490886

Gładyszewski, K., and Skiborowski, M. (2018). Additive Manufacturing of Packings for Rotating Packed Beds. Chem. Eng. Process. - Process Intensification 127, 1-9. doi:10.1016/j.cep.2018.02.024

Gordeev, E. G., and Ananikov, V. P. (2020). Widely Accessible 3D Printing Technologies in Chemistry, Biochemistry and Pharmaceutics: Applications, Materials and Prospects. Russ. Chem. Rev. 89, 1507-1561. doi:10.1070/rcr4980

Govender, S., and Friedrich, H. (2017). Monoliths: A Review of the Basics, Preparation Methods and Their Relevance to Oxidation. Catalysts 7, 62. doi:10.3390/catal7020062

Grande, C. A., Blom, R., Middelkoop, V., Matras, D., Vamvakeros, A., Jacques, S. D. M., et al. (2020). Multiscale Investigation of Adsorption Properties of Novel 3D Printed UTSA-16 Structures. Chem. Eng. J. 402, 126166. doi:10.1016/j.cej.2020. 126166

Groppi, G., Giani, L., and Tronconi, E. (2007). Generalized Correlation for Gas/ Solid Mass-Transfer Coefficients in Metallic and Ceramic Foams. Ind. Eng. Chem. Res. 46, 3955-3958. doi:10.1021/ie061330g

Groppi, G., Tronconi, E., Cortelli, C., and Leanza, R. (2012). Conductive Monolithic Catalysts: Development and Industrial Pilot Tests for the Oxidation of O-Xylene to Phthalic Anhydride. Ind. Eng. Chem. Res. 51, 7590-7596. doi:10.1021/ie2021653

Groppi, G., and Tronconi, E. (2000). Design of Novel Monolith Catalyst Supports for Gas/solid Reactions with Heat Exchange. Chem. Eng. Sci. 55, 2161-2171. doi:10.1016/s0009-2509(99)00440-6

Gunn, D. J. (1978). Transfer of Heat or Mass to Particles in Fixed and Fluidised Beds. Int. J. Heat Mass Transfer 21, 467-476. doi:10.1016/0017-9310(78) 90080-7

Guo, N., and Leu, M. C. (2013). Additive Manufacturing: Technology, Applications and Research Needs. Front. Mech. Eng. 8, 215-243. doi:10.1007/s11465-013$0248-8$

Gupta, V., Nesterenko, P., and Paull, B. (2019b). "CHAPTER 1. An Introduction to 3D Printing," in 3D Printing in Chemical Sciences: Applications across Chemistry (London: Royal Society of Chemistry), 1-21. doi:10.1039/ 9781788015745-00001

Gupta, V., Nesterenko, P., and Paull, B. (2019a). "CHAPTER 2. 3D Printing of Micro- and Macro-Fluidic Devices," in 3D Printing in Chemical Sciences: Applications across Chemistry (London: Royal Society of Chemistry), 22-55. doi:10.1039/9781788015745-00022

Haag, J., Gentric, C., Lemaitre, C., and Leclerc, J.-P. (2018). Modelling of Chemical Reactors: From Systemic Approach to Compartmental Modelling. Int. J. Chem. Reactor Eng. 16, 20170172. doi:10.1515/ijcre-2017-0172

Hagen, J. (2015). "Catalyst Shapes and Production of Heterogeneous Catalysts," in Industrial Catalysis (Hoboken: Wiley VCH), 211-238. doi:10.1002/ 9783527684625.ch6

Hajimirzaee, S., and Doyle, A. M. (2020). 3D Printed Catalytic Converters with Enhanced Activity for Low-Temperature Methane Oxidation in Dual-Fuel Engines. Fuel 274, 117848. doi:10.1016/j.fuel.2020.117848

Hansjosten, E., Wenka, A., Hensel, A., Benzinger, W., Klumpp, M., and Dittmeyer, R. (2018). Custom-designed 3D-Printed Metallic Fluid Guiding Elements for Enhanced Heat Transfer at Low Pressure Drop. Chem. Eng. Process. - Process Intensification 130, 119-126. doi:10.1016/j.cep.2018.05.022

Hargreaves, J. S. J., and Munnoch, A. L. (2013). A Survey of the Influence of Binders in Zeolite Catalysis. Catal. Sci. Technol. 3, 1165-1171. doi:10.1039/c3cy20866d

He, G., Mi, Y., Lock Yue, P., and Chen, G. (1999). Theoretical Study on Concentration Polarization in Gas Separation Membrane Processes. J. Membr. Sci. 153, 243-258. doi:10.1016/S0376-7388(98)00257-9

Heck, R. M., Gulati, S., and Farrauto, R. J. (2001). The Application of Monoliths for Gas Phase Catalytic Reactions. Chem. Eng. J. 82, 149-156. doi:10.1016/s13858947(00)00365-x
Hendershot, D. C. (2018). "Process Intensification for Safety," in Re-Engineering the Chemical Processing Plant. Editors A. I. Stankiewicz and J. A. Moulijn (Boca Raton, FL, USA: CRC Press), 455-477. doi:10.1201/9780203913291-19

Hofmann, D. C., Kolodziejska, J., Roberts, S., Otis, R., Dillon, R. P., Suh, J.-O., et al. (2014). Compositionally Graded Metals: A New Frontier of Additive Manufacturing. J. Mater. Res. 29, 1899-1910. doi:10.1557/jmr.2014.208

Hu, X., Karnetzke, J., Fassbender, M., Drücker, S., Bettermann, S., Schroeter, B., et al. (2020). Smart Reactors - Combining Stimuli-Responsive Hydrogels and 3D Printing. Chem. Eng. J. 387, 123413. doi:10.1016/j.cej.2019.123413

Hurt, C., Brandt, M., Priya, S. S., Bhatelia, T., Patel, J., Selvakannan, P., et al. (2017). Combining Additive Manufacturing and Catalysis: A Review. Catal. Sci. Technol. 7, 3421-3439. doi:10.1039/c7cy00615b

Iveson, S. M., Litster, J. D., Hapgood, K., and Ennis, B. J. (2001). Nucleation, Growth and Breakage Phenomena in Agitated Wet Granulation Processes: A Review. Powder Technol. 117, 3-39. doi:10.1016/s0032-5910(01)00313-8

Jacquot, C., Middelkoop, V., Köckritz, A., Pohar, A., Bienert, R., Kellici, S., et al. (2021). 3D Printed Catalytic Reactors for Aerobic Selective Oxidation of Benzyl Alcohol into Benzaldehyde in Continuous Multiphase Flow. Sustain. Mater. Tech. 30, e00329. doi:10.1016/j.susmat.2021.e00329

Janusziewicz, R., Tumbleston, J. R., Quintanilla, A. L., Mecham, S. J., and DeSimone, J. M. (2016). Layerless Fabrication with Continuous Liquid Interface Production. Proc. Natl. Acad. Sci. USA 113, 11703-11708. doi:10. 1073/pnas.1605271113

Jasra, R. V., Tyagi, B., Badheka, Y. M., Choudary, V. N., and Bhat, T. S. G. (2003). Effect of clay Binder on Sorption and Catalytic Properties of Zeolite Pellets. Ind. Eng. Chem. Res. 42, 3263-3272. doi:10.1021/ie0109531

Jeong, Y., Park, J., and Han, M. (2021). Design and Control of a Fixed-Bed Recycle Reactor with Multicatalyst Layers: Methanation of Carbon Dioxide. Ind. Eng. Chem. Res. 60, 4650-4667. doi:10.1021/acs.iecr.0c05784

Kapteijn, F., and Moulijn, J. A. (2022). Structured Catalysts and Reactors Perspectives for Demanding Applications. Catal. Today 383, 5-14. in press. doi:10.1016/j.cattod.2020.09.026

Karsten, T., Middelkoop, V., Matras, D., Vamvakeros, A., Poulston, S., Grosjean, N., et al. (2020). Multi-Scale Studies of 3D Printed Mn-Na-W/SiO2 Catalyst for Oxidative Coupling of Methane. Catalysts 11, 290. doi:10.3390/catal11030290

Kitson, P. J., Glatzel, S., Chen, W., Lin, C.-G., Song, Y.-F., and Cronin, L. (2016). 3D Printing of Versatile Reactionware for Chemical Synthesis. Nat. Protoc. 11, 920-936. doi:10.1038/nprot.2016.041

Kitson, P. J., Rosnes, M. H., Sans, V., Dragone, V., and Cronin, L. (2012). Configurable 3D-Printed Millifluidic and Microfluidic 'lab on a Chip' Reactionware Devices. Lab. Chip 12, 3267-3271. doi:10.1039/c2lc40761b

Kizilaslan, M. A., Demirel, E., and Aral, M. M. (2018). Effect of Porous Baffles on the Energy Performance of Contact Tanks in Water Treatment. Water 10, 1084. doi: $10.3390 /$ w10081084

Klumpp, M., Inayat, A., Schwerdtfeger, J., Körner, C., Singer, R. F., Freund, H., et al. (2014). Periodic Open Cellular Structures with Ideal Cubic Cell Geometry: Effect of Porosity and Cell Orientation on Pressure Drop Behavior. Chem. Eng. J. 242, 364-378. doi:10.1016/j.cej.2013.12.060

Kong, X., Qiu, M., Wang, A., Yang, L., Zhou, R., Fan, Y., et al. (2018). Influence of Alumina Binders on Adhesion and Cohesion during Preparation of Cu-SAPO34/monolith Catalysts. Int. J. Appl. Ceram. Technol. 15, 1490-1501. doi:10. 1111/ijac. 13008

Kotz, F., Risch, P., Helmer, D., and Rapp, B. E. (2019). High-Performance Materials for 3D Printing in Chemical Synthesis Applications. Adv. Mater. 31, 1805982. doi:10.1002/adma.201805982

Kowsari, K., Akbari, S., Wang, D., Fang, N. X., and Ge, Q. (2018). High-Efficiency High-Resolution Multimaterial Fabrication for Digital Light Processing-Based Three-Dimensional Printing. 3D Printing and Additive Manufacturing 5, 185-193. doi:10.1089/3dp.2018.0004

Kramer, M., McKelvie, M., and Watson, M. (2018). Additive Manufacturing of Catalyst Substrates for Steam-Methane Reforming. J. Materi Eng. Perform. 27, 21-31. doi:10.1007/s11665-017-2859-4

Kraushaar-Czarnetzki, B., and Peter Mller, S. (2009). "Shaping of Solid Catalysts," in Synthesis of Solid Catalysts. Editor K. de Jong (Weinheim: Wiley VCH), 173-199. doi:10.1002/9783527626854.ch9

Kreutzer, M. T., Bakker, J. J. W., Kapteijn, F., Moulijn, J. A., and Verheijen, P. J. T. (2005). Scaling-up Multiphase Monolith Reactors: Linking Residence Time 
Distribution and Feed Maldistribution. Ind. Eng. Chem. Res. 44, 4898-4913. doi:10.1021/ie0492350

Kruth, J. P., Mercelis, P., Van Vaerenbergh, J., Froyen, L., and Rombouts, M. (2005). Binding Mechanisms in Selective Laser Sintering and Selective Laser Melting. Rapid Prototyping J. 11, 26-36. doi:10.1108/13552540510573365

Kuang, X., Carotenuto, G., and Nicolais, L. (1997). A Review of Ceramic Sintering and Suggestions on Reducing Sintering Temperatures. Adv. Perform. Mater. 4, 257-274. doi:10.1023/A:1008621020555

[Dataset] Lai, W. F., Podsiadlo, P., Rollman, N. S., and Benitez, K. M. (2018). Modified Trilobe and Quadrilobe Shaped Catalyst Extrudates. WO2019055220A1. Geneva: World Intellectual Property Organization.

Lakiss, L., Gilson, J.-P., Valtchev, V., Mintova, S., Vicente, A., Vimont, A., et al. (2020). Zeolites in a Good Shape: Catalyst Forming by Extrusion Modifies Their Performances. Microporous Mesoporous Mater. 299, 110114. doi:10.1016/j. micromeso.2020.110114

Lämmermann, M., Horak, G., Schwieger, W., and Freund, H. (2018). Periodic Open Cellular Structures (POCS) for Intensification of Multiphase Reactors: Liquid Holdup and Two-phase Pressure Drop. Chem. Eng. Process. - Process Intensification 126, 178-189. doi:10.1016/j.cep.2018.02.027

Lawson, S., Adebayo, B., Robinson, C., Al-Naddaf, Q., Rownaghi, A. A., and Rezaei, F. (2020). The Effects of Cell Density and Intrinsic Porosity on Structural Properties and Adsorption Kinetics in 3D-Printed Zeolite Monoliths. Chem. Eng. Sci. 218, 115564. doi:10.1016/j.ces.2020.115564

Lawson, S., Baamran, K., Newport, K., Rezaei, F., and Rownaghi, A. (2021a). Screening of Adsorbent/catalyst Composite Monoliths for Carbon CaptureUtilization and Ethylene Production. ACS Appl. Mater. Inter. 13, 55198-55207. doi:10.1021/acsami.1c17668

Lawson, S., Li, X., Thakkar, H., Rownaghi, A. A., and Rezaei, F. (2021b). Recent Advances in 3D Printing of Structured Materials for Adsorption and Catalysis Applications. Chem. Rev. 121, 6246-6291. doi:10.1021/acs. chemrev.1c00060

Lawson, S., Newport, K., Al-Naddaf, Q., Ameh, A. E., Rownaghi, A. A., Petrik, L. F., et al. (2021c). Binderless Zeolite Monoliths Production with Sacrificial Biopolymers. Chem. Eng. J. 407, 128011. doi:10.1016/j.cej. 2020.128011

Lefevere, J., Mullens, S., and Meynen, V. (2018). The Impact of Formulation and 3D-Printing on the Catalytic Properties of ZSM-5 Zeolite. Chem. Eng. J. 349, 260-268. doi:10.1016/j.cej.2018.05.058

Lefevere, J., Protasova, L., Mullens, S., and Meynen, V. (2017). 3D-printing of Hierarchical Porous ZSM-5: The Importance of the Binder System. Mater. Des. 134, 331-341. doi:10.1016/j.matdes.2017.08.044

Lerou, J. J., and Froment, G. F. (1977). Velocity, Temperature and Conversion Profiles in Fixed Bed Catalytic Reactors. Chem. Eng. Sci. 32, 853-861. doi:10. 1016/0009-2509(77)80071-7

Levenspiel, O., and Bischoff, K. B. (1959). Backmixing in the Design of Chemical Reactors. Ind. Eng. Chem. 51, 1431-1434. doi:10.1021/ie50600a023

Lewis, J. A. (2006). Direct Ink Writing of 3D Functional Materials. Adv. Funct. Mater. 16, 2193-2204. doi:10.1002/adfm.200600434

Lewis, J. A., Smay, J. E., Stuecker, J., and Cesarano, J. (2006). Direct Ink Writing of Three-Dimensional Ceramic Structures. J. Am. Ceram. Soc. 89, 3599-3609. doi:10.1111/j.1551-2916.2006.01382.x

Li, H., and Kottke, V. (1998). Effect of Baffle Spacing on Pressure Drop and Local Heat Transfer in Shell-And-Tube Heat Exchangers for Staggered Tube Arrangement. Int. J. Heat Mass Transfer 41, 1303-1311. doi:10.1016/s00179310(97)00201-9

Li, H., Liu, Y., Liu, Y., Hu, K., Lu, Z., and Liang, J. (2020a). Effects of Solvent Debinding on the Microstructure and Properties of 3D-Printed Alumina Ceramics. ACS Omega 5, 27455-27462. doi:10.1021/acsomega.0c03944

Li, Y., Zhang, Q., Chai, R., Zhao, G., Liu, Y., Lu, Y., et al. (2015). Ni-Al2O3/Ni-foam Catalyst with Enhanced Heat Transfer for Hydrogenation of $\mathrm{CO} 2$ to Methane. Aiche J. 61, 4323-4331. doi:10.1002/aic.14935

Li, Y., Zhao, J., and Chang, L. (1991). "Factors Analysis for Mechanical Strength in Pelleting Process of Fe-Based High Temperature Shift Catalyst," in Preparation of Catalysts V. Editors G. Poncelet, P. Jacobs, P. Grange, and B. Delmon (Amsterdam: Elsevier), 145-153. doi:10.1016/S0167-2991(08)64581-4

Li, Z., Jiang, X., Xiong, G., Nie, B., Liu, C., He, N., et al. (2020b). Towards the Preparation of Binderless ZSM-5 Zeolite Catalysts: The Crucial Role of Silanol Nests. Catal. Sci. Technol. 10, 7829-7841. doi:10.1039/d0cy01289k
Lim, G. J. H., Wu, Y., Shah, B. B., Koh, J. J., Liu, C. K., Zhao, D., et al. (2019). 3DPrinting of Pure Metal-Organic Framework Monoliths. ACS Mater. Lett. 1, 147-153. doi:10.1021/acsmaterialslett.9b00069

Lind, A., Vistad, Ø., Sunding, M. F., Andreassen, K. A., Cavka, J. H., and Grande, C. A. (2020). Multi-purpose Structured Catalysts Designed and Manufactured by 3D Printing. Mater. Des. 187, 108377. doi:10.1016/j.matdes.2019.108377

Litster, J., and Ennis, B. (2004). The Science and Engineering of Granulation Processes, Vol. 15 of Particle Technology Series. Dordrecht: Springer. doi:10. 1007/978-94-017-0546-2

Liu, D., Jiang, P., Li, X., Liu, J., Zhou, L., Wang, X., et al. (2020). 3D Printing of Metal-Organic Frameworks Decorated Hierarchical Porous Ceramics for HighEfficiency Catalytic Degradation. Chem. Eng. J. 397, 125392. doi:10.1016/j.cej. 2020.125392

Lucci, F., Della Torre, A., Montenegro, G., Kaufmann, R., and Dimopoulos Eggenschwiler, P. (2017). Comparison of Geometrical, Momentum and Mass Transfer Characteristics of Real Foams to Kelvin Cell Lattices for Catalyst Applications. Int. J. Heat Mass Transfer 108, 341-350. doi:10.1016/ j.ijheatmasstransfer.2016.11.073

Magzoub, F., Li, X., Al-Darwish, J., Rezaei, F., and Rownaghi, A. A. (2019). 3Dprinted ZSM-5 Monoliths with Metal Dopants for Methanol Conversion in the Presence and Absence of Carbon Dioxide. Appl. Catal. B: Environ. 245, 486-495. doi:10.1016/j.apcatb.2019.01.008

Manzano, J. S., Weinstein, Z. B., Sadow, A. D., and Slowing, I. I. (2017). Direct 3D Printing of Catalytically Active Structures. ACS Catal. 7, 7567-7577. doi:10. 1021/acscatal.7b02111

Mardani, S., Ojala, L. S., Uusi-Kyyny, P., and Alopaeus, V. (2016). Development of a Unique Modular Distillation Column Using 3D Printing. Chem. Eng. Process. - Process Intensification 109, 136-148. doi:10.1016/j.cep.2016.09.001

Marek, M. (2013). Numerical Generation of a Fixed Bed Structure. Chem. Process Eng. 34, 347-359. doi:10.2478/cpe-2013-0028

Martavaltzi, C. S., and Lemonidou, A. A. (2010). Hydrogen Production via Sorption Enhanced Reforming of Methane: Development of a Novel Hybrid Material-Reforming Catalyst and CO2 Sorbent. Chem. Eng. Sci. 65, 4134-4140. doi:10.1016/j.ces.2010.04.038

Martínez, S., Veth, L., Lainer, B., and Dydio, P. (2021). Challenges and Opportunities in Multicatalysis. ACS Catal. 11, 3891-3915. doi:10.1021/ acscatal.0c05725

M'Barki, A., Bocquet, L., and Stevenson, A. (2017). Linking Rheology and Printability for Dense and Strong Ceramics by Direct Ink Writing. Sci. Rep. 7, 1-10. doi:10.1038/s41598-017-06115-0

Middelkoop, V., Coenen, K., Schalck, J., van Sint Annaland, M., and Gallucci, F. (2019a). 3D Printed versus Spherical Adsorbents for Gas Sweetening. Chem. Eng. J. 357, 309-319. doi:10.1016/j.cej.2018.09.130

Middelkoop, V., Vamvakeros, A., de Wit, D., Jacques, S. D. M., Danaci, S., Jacquot, C., et al. (2019b). 3D Printed Ni/Al2O3 Based Catalysts for CO2 Methanation a Comparative and Operando XRD-CT Study. J. CO2 Utilization 33, 478-487. doi:10.1016/j.jcou.2019.07.013

Mitchell, S., Michels, N.-L., Kunze, K., and Pérez-Ramírez, J. (2012). Visualization of Hierarchically Structured Zeolite Bodies from Macro to Nano Length Scales. Nat. Chem 4, 825-831. doi:10.1038/nchem.1403

Mitchell, S., Michels, N.-L., and Pérez-Ramírez, J. (2013). From Powder to Technical Body: The Undervalued Science of Catalyst Scale up. Chem. Soc. Rev. 42, 6094-6112. doi:10.1039/c3cs60076a

Mizuno, K., Nishiyama, Y., Ogaki, T., Terao, K., Ikeda, H., and Kakiuchi, K. (2016). Utilization of Microflow Reactors to Carry Out Synthetically Useful Organic Photochemical Reactions. J. Photochem. Photobiol. C: Photochem. Rev. 29, 107-147. doi:10.1016/j.jphotochemrev.2016.10.002

Moghaddam, E. M., Foumeny, E. A., Stankiewicz, A. I., and Padding, J. T. (2019). Fixed Bed Reactors of Non-spherical Pellets: Importance of Heterogeneities and Inadequacy of Azimuthal Averaging. Chem. Eng. Sci. X 1, 100006. doi:10.1016/j. cesx.2019.100006

Nauman, E. B. (1981). Residence Time Distributions and Micromixing. Chem. Eng. Commun. 8, 53-131. doi:10.1080/00986448108912576

Nawada, S., Dimartino, S., and Fee, C. (2017). Dispersion Behavior of 3D-Printed Columns with Homogeneous Microstructures Comprising Differing Element Shapes. Chem. Eng. Sci. 164, 90-98. doi:10.1016/j.ces.2017.02.012

Newberger, M. R., and Kadlec, R. H. (1971). Optimal Operation of a Tubular Chemical Reactor. Aiche J. 17, 1381-1387. doi:10.1002/aic.690170619 
Ngo, T. D., Kashani, A., Imbalzano, G., Nguyen, K. T. Q., and Hui, D. (2018). Additive Manufacturing (3D Printing): A Review of Materials, Methods, Applications and Challenges. Composites B: Eng. 143, 172-196. doi:10.1016/ j.compositesb.2018.02.012

Nguyen, X., Carafa, A., and Hornung, C. H. (2018). Hydrogenation of Vinyl Acetate Using a Continuous Flow Tubular Reactor with Catalytic Static Mixers. Chem. Eng. Process. - Process Intensification 124, 215-221. doi:10.1016/j.cep. 2017.12.007

Nickels, L. (2015). AM and Aerospace: An Ideal Combination. Metal Powder Rep. 70, 300-303. doi:10.1016/j.mprp.2015.06.005

Nijhuis, T. A., Beers, A. E. W., Vergunst, T., Hoek, I., Kapteijn, F., and Moulijn, J. A. (2001). Preparation of Monolithic Catalysts. Catal. Rev. 43, 345-380. doi:10. 1081/CR-120001807

Nooijer, N., Arratibel Plazaola, A., Meléndez Rey, J., Fernandez, E., Pacheco Tanaka, D., Sint Annaland, M., et al. (2019). Long-Term Stability of ThinFilm Pd-Based Supported Membranes. Processes 7, 106. doi:10.3390/pr7020106

Novak, L. T., and Mateer, D. D. (1986). Trickling Flow Pressure Drop in Packed Beds of Formed Catalysts. Ind. Eng. Chem. Proc. Des. Dev. 25, 1034-1036. doi:10.1021/i200035a 032

Ovsienko, O. L. (2009). Investigation of Pelletization Stage and its Role in the Formation of Catalyst Quality Indices. Catal. Ind. 1, 367-380. doi:10.1134/ s2070050409040138

Ozahi, E., Gundogdu, M. Y., and Carpinlioglu, M. Ö. (2008). A Modification on Ergun's Correlation for Use in Cylindrical Packed Beds with Non-spherical Particles. Adv. Powder Technol. 19, 369-381. doi:10.1163/156855208x314985

Pangarkar, K., Schildhauer, T. J., van Ommen, J. R., Nijenhuis, J., Kapteijn, F., and Moulijn, J. A. (2008). Structured Packings for Multiphase Catalytic Reactors. Ind. Eng. Chem. Res. 47, 3720-3751. doi:10.1021/ie800067r

Papetti, V., Dimopoulos Eggenschwiler, P., Della Torre, A., Lucci, F., Ortona, A., and Montenegro, G. (2018). Additive Manufactured Open Cell Polyhedral Structures as Substrates for Automotive Catalysts. Int. J. Heat Mass Transfer 126, 1035-1047. doi:10.1016/j.ijheatmasstransfer.2018.06.061

Papetti, V., Dimopoulos Eggenschwiler, P., Della Torre, A., Montenegro, G., Onorati, A., Ortona, A., et al. (2021). Instationary Heat and Mass Transfer Phenomena in Additive Manufactured Open Cell Polyhedral Structures for Automotive Catalysis. Chem. Eng. Sci. 234, 116448. doi:10.1016/j.ces.2021. 116448

Parra-Cabrera, C., Achille, C., Kuhn, S., and Ameloot, R. (2018). 3D Printing in Chemical Engineering and Catalytic Technology: Structured Catalysts, Mixers and Reactors. Chem. Soc. Rev. 47, 209-230. doi:10.1039/c7cs00631d

Patcas, F. C., Garrido, G. I., and Kraushaar-Czarnetzki, B. (2007). CO Oxidation over Structured Carriers: A Comparison of Ceramic Foams, Honeycombs and Beads. Chem. Eng. Sci. 62, 3984-3990. doi:10.1016/j.ces.2007.04.039

Pellejero, I., Almazán, F., Lafuente, M., Urbiztondo, M. A., Drobek, M., Bechelany, M., et al. (2020). Functionalization of 3D Printed ABS Filters with MOF for Toxic Gas Removal. J. Ind. Eng. Chem. 89, 194-203. doi:10.1016/j.jiec.2020.05.013

Peng, E., Zhang, D., and Ding, J. (2018). Ceramic Robocasting: Recent Achievements, Potential, and Future Developments. Adv. Mater. 30, 1802404. doi:10.1002/adma.201802404

Pérez-Ramírez, J., Mitchell, S., Verboekend, D., Milina, M., Michels, N.-L., Krumeich, F., et al. (2011). Expanding the Horizons of Hierarchical Zeolites: Beyond Laboratory Curiosity towards Industrial Realization. ChemCatChem 3, 1731-1734. doi:10.1002/cctc.201100264

Pestryakov, A. N., Yurchenko, E. N., and Feofilov, A. E. (1996). Foam-metal Catalysts for Purification of Waste Gases and Neutralization of Automotive Emissions. Catal. Today 29, 67-70. doi:10.1016/0920-5861(95)00266-9

Pottbäcker, J., and Hinrichsen, O. (2017). Experimental Study on the Influence of Filling Method and Particle Material on the Packed-Bed Porosity. Chem. Ingenieur Technik 89, 454-458. doi:10.1002/cite.201600151

Prater, T., Werkheiser, N., Ledbetter, F., Timucin, D., Wheeler, K., and Snyder, M. (2018). 3d Printing in Zero G Technology Demonstration mission: Complete Experimental Results and Summary of Related Material Modeling Efforts. Int. J. Adv. Manuf Technol. 101, 391-417. doi:10.1007/s00170-018-2827-7

Qian, B., and Shen, Z. (2013). Laser Sintering of Ceramics. J. Asian Ceram. Societies 1, 315-321. doi:10.1016/j.jascer.2013.08.004

Raouf, F., Taghizadeh, M., and Yousefi, M. (2014). Single and Multi-Channel Reactor for Oxidative Coupling of Methane. Int. J. Chem. Reactor Eng. 12, 181-189. doi:10.1515/ijcre-2013-0161
Ravindran, K., and Madhu, G. (2020). Impact of Shape and Size of Catalysts on the Physical Properties and Pressure Drop in Fixed Bed Catalytic Systems. Ijitee 9, 1103-1109. doi:10.35940/ijitee.f4214.049620

Raynaud, J., Pateloup, V., Bernard, M., Gourdonnaud, D., Passerieux, D., Cros, D., et al. (2020). Hybridization of Additive Manufacturing Processes to Build Ceramic/metal Parts: Example of LTCC. J. Eur. Ceram. Soc. 40, 759-767. doi:10. 1016/j.jeurceramsoc.2019.10.019

Raynaud, J., Pateloup, V., Bernard, M., Gourdonnaud, D., Passerieux, D., Cros, D., et al. (2021). Hybridization of Additive Manufacturing Processes to Build Ceramic/metal Parts: Example of HTCC. J. Eur. Ceram. Soc. 41, 2023-2033. doi:10.1016/j.jeurceramsoc.2020.10.032

Regufe, M. J., Ferreira, A. F. P., Loureiro, J. M., Rodrigues, A., and Ribeiro, A. M. (2019). Electrical Conductive 3D-Printed Monolith Adsorbent for $\mathrm{CO} 2$ Capture. Microporous Mesoporous Mater. 278, 403-413. doi:10.1016/j. micromeso.2019.01.009

Rezaei, F., and Webley, P. (2010). Structured Adsorbents in Gas Separation Processes. Separat. Purif. Technol. 70, 243-256. doi:10.1016/j.seppur.2009. 10.004

Roy, S., Bauer, T., Al-Dahhan, M., Lehner, P., and Turek, T. (2004). Monoliths as Multiphase Reactors: A Review. Aiche J. 50, 2918-2938. doi:10.1002/aic.10268

Sagandira, C. R., Siyawamwaya, M., and Watts, P. (2020). 3D Printing and Continuous Flow Chemistry Technology to advance Pharmaceutical Manufacturing in Developing Countries. Arabian J. Chem. 13, 7886-7908. doi:10.1016/j.arabjc.2020.09.020

Salvat, W. I., Mariani, N. J., Barreto, G. F., and Martínez, O. M. (2005). An Algorithm to Simulate Packing Structure in Cylindrical Containers. Catal. Today 107-108, 513-519. doi:10.1016/j.cattod.2005.07.108

Sanchez Díaz-Marta, A., Yáñez, S., Tubío, C. R., Barrio, V. L., Piñeiro, Y., Pedrido, R., et al. (2019). Multicatalysis Combining 3D-Printed Devices and Magnetic Nanoparticles in One-Pot Reactions: Steps Forward in Compartmentation and Recyclability of Catalysts. ACS Appl. Mater. Inter. 11, 25283-25294. doi:10. 1021/acsami.9b08119

Sans, V. (2020). Emerging Trends in Flow Chemistry Enabled by 3D Printing: Robust Reactors, Biocatalysis and Electrochemistry. Curr. Opin. Green Sustain. Chem. 25, 100367. doi:10.1016/j.cogsc.2020.100367

Santoliquido, O., Bianchi, G., Dimopoulos Eggenschwiler, P., and Ortona, A. (2017). Additive Manufacturing of Periodic Ceramic Substrates for Automotive Catalyst Supports. Int. J. Appl. Ceram. Technol. 14, 1164-1173. doi:10.1111/ijac. 12745

Scarfiello, C., Bellusci, M., Pilloni, L., Pietrogiacomi, D., La Barbera, A., and Varsano, F. (2021). Supported Catalysts for Induction-Heated Steam Reforming of Methane. Int. J. Hydrogen Energ. 46, 134-145. doi:10.1016/j. ijhydene.2020.09.262

Schwieger, W., Machoke, A. G., Weissenberger, T., Inayat, A., Selvam, T., Klumpp, M., et al. (2016). Hierarchy Concepts: Classification and Preparation Strategies for Zeolite Containing Materials with Hierarchical Porosity. Chem. Soc. Rev. 45, 3353-3376. doi:10.1039/c5cs00599j

Shakor, P., Nejadi, S., Paul, G., and Sanjayan, J. (2020). Dimensional Accuracy, Flowability, Wettability, and Porosity in Inkjet 3dp for gypsum and Cement Mortar Materials. Automation in Construction 110, 102964. doi:10.1016/j. autcon.2019.102964

Shang, H., Mohanram, A., and Bordia, R. K. (2015). Densification and Microstructural Evolution of Hierarchically Porous Ceramics during Sintering. J. Am. Ceram. Soc. 98, 3424-3430. doi:10.1111/jace.13812

Shanmugam, S. (2015). Granulation Techniques and Technologies: Recent Progresses. Bioimpacts 5, 55-63. doi:10.15171/bi.2015.04

Shen, Z., Ma, C., He, J., Wang, D., Sun, H., Zhu, Z., et al. (2019). Preparation of a Shaped Core-Shell Structured Binder-free ZSM-5 Catalyst and its Application for Benzene Alkylation with Ethylene. Appl. Catal. A: Gen. 577, 20-27. doi:10. 1016/j.apcata.2019.03.006

Shinnar, R., Doyle, F. J., Budman, H. M., and Morari, M. (1992). Design Considerations for Tubular Reactors with Highly Exothermic Reactions. Aiche J. 38, 1729-1743. doi:10.1002/aic.690381106

Silla, H. (2003). Chemical Process Engineering: Design and Economics. Boca Raton, FL, USA: CRC Press. doi:10.1201/9780203912454

Simon, U., and Dimartino, S. (2019). Direct 3D Printing of Monolithic Ion Exchange Adsorbers. J. Chromatogr. A 1587, 119-128. doi:10.1016/j.chroma. 2018.12.017 
Smay, J. E., Gratson, G. M., Shepherd, R. F., Cesarano, J., and Lewis, J. A. (2002). Directed Colloidal Assembly of 3D Periodic Structures. Adv. Mater. 14, 1279-1283. doi:10.1002/1521-4095(20020916)14:18<1279:aid-adma1279>3.0. co;2-a

Somton, K., Dateraksa, K., Laoratanakul, P., and Mccuiston, R. (2020). Shrinkage and properties of die pressed alumina produced from different granule sources. AIP Conf. Proc. 2279, 60002. doi:10.1063/5.0023313

Studart, A. R., Gonzenbach, U. T., Tervoort, E., and Gauckler, L. J. (2006). Processing Routes to Macroporous Ceramics: A Review. J. Am. Ceram. Soc. 89, 1771-1789. doi:10.1111/j.1551-2916.2006.01044.x

Stutz, M. J., and Poulikakos, D. (2008). Optimum Washcoat Thickness of a Monolith Reactor for Syngas Production by Partial Oxidation of Methane. Chem. Eng. Sci. 63, 1761-1770. doi:10.1016/j.ces.2007.11.032

Sun, J., Chen, X., Wade-Zhu, J., Binner, J., and Bai, J. (2021). A Comprehensive Study of Dense Zirconia Components Fabricated by Additive Manufacturing. Additive Manufacturing 43, 101994. doi:10.1016/j.addma.2021.101994

Sun, X., Yan, Y., Zhang, L., Ma, G., Liu, Y., Yu, Y., et al. (2018). Direct 3D Printing of Reactive Agitating Impellers for the Convenient Treatment of Various Pollutants in Water. Adv. Mater. Inter. 5, 1701626. doi:10.1002/admi. 201701626

Téllez-Medina, D. I., Byrne, E., Fitzpatrick, J., Catak, M., and Cronin, K. (2010). Relationship between Mechanical Properties and Shape Descriptors of Granules Obtained by Fluidized Bed Wet Granulation. Chem. Eng. J. 164, 425-431. doi:10.1016/j.cej.2009.11.035

Thakkar, H., Eastman, S., Hajari, A., Rownaghi, A. A., Knox, J. C., and Rezaei, F. (2016). 3D-Printed Zeolite Monoliths for CO2 Removal from Enclosed Environments. ACS Appl. Mater. Inter. 8, 27753-27761. doi:10.1021/acsami. 6b09647

Thiele, E. W. (1939). Relation between Catalytic Activity and Size of Particle. Ind. Eng. Chem. 31, 916-920. doi:10.1021/ie50355a027

Thijs, I., Luyten, J., and Mullens, S. (2004). Producing Ceramic Foams with Hollow Spheres. J. Am. Ceram. Soc. 87, 170-172. doi:10.1111/j.1151-2916.2004.tb19965.x

Thompson, J. F., Bellerjeau, C., Marinick, G., Osio-Norgaard, J., Evans, A., Carry, P., et al. (2019). Intrinsic thermal Desorption in a 3d Printed Multifunctional Composite Co2 Sorbent with Embedded Heating Capability. ACS Appl. Mater. Inter. 11, 43337-43343. doi:10.1021/acsami.9b14111

Tomašić, V., and Jović, F. (2006). State-of-the-art in the Monolithic Catalysts/ reactors. Appl. Catal. A: Gen. 311, 112-121. doi:10.1016/j.apcata.2006.06.013

Travitzky, N., Bonet, A., Dermeik, B., Fey, T., Filbert-Demut, I., Schlier, L., et al. (2014). Additive Manufacturing of Ceramic-Based Materials. Adv. Eng. Mater. 16, 729-754. doi:10.1002/adem.201400097

Tubío, C. R., Azuaje, J., Escalante, L., Coelho, A., Guitián, F., Sotelo, E., et al. (2016). 3D Printing of a Heterogeneous Copper-Based Catalyst. J. Catal. 334, 110-115. doi:10.1016/j.jcat.2015.11.019

Twigg, M. V., and Richardson, J. T. (2007). Fundamentals and Applications of Structured Ceramic Foam Catalysts. Ind. Eng. Chem. Res. 46, 4166-4177. doi:10.1021/ie061122o

Twigg, M. V., and Richardson, J. T. (2002). Theory and Applications of Ceramic Foam Catalysts. Chem. Eng. Res. Des. 80, 183-189. doi:10.1205/ 026387602753501906

Vaezi, M., Chianrabutra, S., Mellor, B., and Yang, S. (2013). Multiple Material Additive Manufacturing - Part 1: A Review. Virtual Phys. Prototyping 8, 19-50. doi:10.1080/17452759.2013.778175

Vajglová, Z., Kumar, N., Mäki-Arvela, P., Eränen, K., Peurla, M., Hupa, L., et al. (2019). Effect of Binders on the Physicochemical and Catalytic Properties of Extrudate-Shaped Beta Zeolite Catalysts for Cyclization of Citronellal. Org. Process. Res. Dev. 23, 2456-2463. doi:10.1021/acs.oprd.9b00346

van Herk, D., Castaño, P., Quaglia, M., Kreutzer, M. T., Makkee, M., and Moulijn, J. A. (2009). Avoiding Segregation during the Loading of a Catalyst-Inert Powder Mixture in a Packed Micro-bed. Appl. Catal. A: Gen. 365, 110-121. doi:10.1016/j.apcata.2009.06.003

Vandewalle, L. A., Van de Vijver, R., Van Geem, K. M., and Marin, G. B. (2019). The Role of Mass and Heat Transfer in the Design of Novel Reactors for Oxidative Coupling of Methane. Chem. Eng. Sci. 198, 268-289. doi:10.1016/j. ces.2018.09.022

Varghese, G., Moral, M., Castro-García, M., López-López, J. J., Marín-Rueda, J. R., Yagüe-Alcaraz, V., et al. (2018). Fabrication and Characterisation of Ceramics via Low-Cost DLP 3D Printing. Boletín de la Sociedad Española de Cerámica y Vidrio 57, 9-18. doi:10.1016/j.bsecv.2017.09.004

Vernuccio, S., Dempfle, D., Goy, R., Medlock, J., and Rudolf von Rohr, P. (2018). External Mass Transfer in a Laser Sintered Structured Reactor for Continuous Hydrogenation of Alkynes. Chem. Eng. Process. - Process Intensification 126, 74-80. doi:10.1016/j.cep.2018.02.005

Vervloet, D., Kapteijn, F., Nijenhuis, J., and Van Ommen, J. R. (2013). Process Intensification of Tubular Reactors: Considerations on Catalyst Hold-Up of Structured Packings. Catal. Today 216, 111-116. doi:10.1016/j.cattod.2013. 05.019

Visconti, C. G., Groppi, G., and Tronconi, E. (2016). Highly Conductive "packed Foams": A New Concept for the Intensification of Strongly Endo- and ExoThermic Catalytic Processes in Compact Tubular Reactors. Catal. Today 273, 178-186. doi:10.1016/j.cattod.2016.02.060

Waldram, S. P. (1985). "Chapter 6 Non-ideal Flow in Chemical Reactors," in Kinetics and Chemical Technology. Vol. 23 of Comprehensive Chemical Kinetics. Editors C. Bamford, C. Tipper, and R. Compton (Amsterdam, Netherlands: Elsevier), 223-281. doi:10.1016/s0069-8040(08)70148-1

Wang, S., Bai, P., Sun, M., Liu, W., Li, D., Wu, W., et al. (2019a). Fabricating Mechanically Robust Binder-Free Structured Zeolites by 3D Printing Coupled with Zeolite Soldering: A Superior Configuration for CO2 Capture. Adv. Sci. 6, 1901317. doi:10.1002/advs.201901317

Wang, W., Tuci, G., Duong-Viet, C., Liu, Y., Rossin, A., Luconi, L., et al. (2019b). Induction Heating: An Enabling Technology for the Heat Management in Catalytic Processes. ACS Catal. 9, 7921-7935. doi:10. 1021/acscatal.9b02471

Wang, X., Guo, W., Abu-Reziq, R., and Magdassi, S. (2020). High-Complexity WO3-Based Catalyst with Multi-Catalytic Species via 3D Printing. Catalysts 10, 840. doi:10.3390/catal10080840

Wei, Q., Li, H., Liu, G., He, Y., Wang, Y., Tan, Y. E., et al. (2020). Metal 3D Printing Technology for Functional Integration of Catalytic System. Nat. Commun. 11, 1-8. doi:10.1038/s41467-020-17941-8

Whiting, G. T., Chung, S.-H., Stosic, D., Chowdhury, A. D., Van Der Wal, L. I., Fu, D., et al. (2019). Multiscale Mechanistic Insights of Shaped Catalyst Body Formulations and Their Impact on Catalytic Properties. ACS Catal. 9, 4792-4803. doi:10.1021/acscatal.9b00151

Willemsen, J. A. M., and De Boer, R. (2020). Additive Manufacturing of 3D Ceramic Structures for CO2 Sorption. Carbon Capture J. 2020, 20-22. Available at: https://www.carboncapturejournal.com.

Xu, Y., Ma, H., Yamamoto, Y., Suzuki, Y., and Zhang, Z. (2012). Comparison of the Activities of Binder-Added and Binder-free Mo/HZSM-5 Catalysts in Methane Dehydroaromatization at $1073 \mathrm{~K}$ in Periodic CH4-H2 Switch Operation Mode. J. Nat. Gas Chem. 21, 729-744. doi:10.1016/s10039953(11)60426-X

Xu, Y., Song, Y., and Zhang, Z.-G. (2017). A Binder-free Fluidizable Mo/HZSM-5 Catalyst for Non-oxidative Methane Dehydroaromatization in a Dual Circulating Fluidized Bed Reactor System. Catal. Today 279, 115-123. doi:10.1016/j.cattod.2016.03.037

Yakubovich, M. N., Simonstev, V. I., Vytnov, G. F., Luiksaar, L. S., Lasareva, N. P., Yaremenko, E. I., et al. (1984). The Effect of Forming Methods on the Catalytic Properties of Catalyst Granules for Acrolein Oxidation to Acrylic Acid. Appl. Catal. 10, 297-302. doi:10.1016/0166-9834(84)80124-4

Yang, Y.-T., and Hwang, C.-Z. (2003). Calculation of Turbulent Flow and Heat Transfer in a Porous-Baffled Channel. Int. J. Heat Mass Transfer 46, 771-780. doi:10.1016/s0017-9310(02)00360-5

Yassine, S. R., Fatfat, Z., Darwish, G. H., and Karam, P. (2020). Localized Catalysis Driven by the Induction Heating of Magnetic Nanoparticles. Catal. Sci. Technol. 10, 3890-3896. doi:10.1039/d0cy00439a

Yawalkar, A. A., Sood, R., Kreutzer, M. T., Kapteijn, F., and Moulijn, J. A. (2005). Axial Mixing in Monolith Reactors: Effect of Channel Size. Ind. Eng. Chem. Res. 44, 2046-2057. doi:10.1021/ie049338i

Zakeri, S., Vippola, M., and Levänen, E. (2020). A Comprehensive Review of the Photopolymerization of Ceramic Resins Used in Stereolithography. Additive Manufacturing 35, 101177. doi:10.1016/j.addma.2020.101177

Zentel, K. M., Fassbender, M., Pauer, W., and Luinstra, G. A. (2020). 3D Printing as Chemical Reaction Engineering Booster. Adv. Chem. Eng. 56, 97-137. doi:10. 1016/bs.ache.2020.08.002 
Zhakeyev, A., Wang, P., Zhang, L., Shu, W., Wang, H., and Xuan, J. (2017). Additive Manufacturing: Unlocking the Evolution of Energy Materials. Adv. Sci. 4, 1700187. doi:10.1002/advs.201700187

Zhang, H., Wang, P., Zhang, H., Yang, H., Wang, H., and Zhang, L. (2020). Structured Zeolite Monoliths with Ultrathin Framework for Fast CO2 Adsorption Enabled by 3D Printing. Ind. Eng. Chem. Res. 59, 8223-8229. doi:10.1021/acs.iecr.9b07060

Zhou, H., Wang, X., Wang, X., Peng, C., Wang, R., and Zhou, K. (2021). Principles of Dispersing Powders for 3d Printing. Colloids Inter. 5, 25. doi:10.3390/ colloids5020025

Zhou, X., and Liu, C.-j. (2017). Three-dimensional Printing for Catalytic Applications: Current Status and Perspectives. Adv. Funct. Mater. 27, 1701134. doi:10.1002/adfm.201701134

Zhu, X., Imtiaz, Q., Donat, F., Müller, C. R., and Li, F. (2020). Chemical Looping beyond Combustion - a Perspective. Energy Environ. Sci. 13, 772-804. doi:10. 1039/c9ee03793d

Zimmer, A., PachecoAraújo, J. D., Andreassen, K. A., and Grande, C. A. (2021). Effect of Manufacturing Techniques in Pressure Drop on Triple Periodical Minimal Surface Packings. Chem. Ingenieur Technik 93, 967-973. doi:10.1002/cite.202000237

Zocca, A., Colombo, P., Gomes, C. M., and Günster, J. (2015). Additive Manufacturing of Ceramics: Issues, Potentialities, and Opportunities. J. Am. Ceram. Soc. 98, 1983-2001. doi:10.1111/jace.13700
Zou, R. P., and Yu, A. B. (1996). Evaluation of the Packing Characteristics of Mono-Sized Non-spherical Particles. Powder Technol. 88, 71-79. doi:10.1016/0032-5910(96)03106-3

Conflict of Interest: Author HW was employed by company 3D-cat B.V.

The remaining authors declare that the research was conducted in the absence of any commercial or financial relationships that could be construed as a potential conflict of interest.

Publisher's Note: All claims expressed in this article are solely those of the authors and do not necessarily represent those of their affiliated organizations, or those of the publisher, the editors and the reviewers. Any product that may be evaluated in this article, or claim that may be made by its manufacturer, is not guaranteed or endorsed by the publisher.

Copyright (C) 2022 Rosseau, Middelkoop, Willemsen, Roghair and van Sint Annaland. This is an open-access article distributed under the terms of the Creative Commons Attribution License (CC BY). The use, distribution or reproduction in other forums is permitted, provided the original author(s) and the copyright owner(s) are credited and that the original publication in this journal is cited, in accordance with accepted academic practice. No use, distribution or reproduction is permitted which does not comply with these terms. 